\title{
Off-exchange trading and post earnings announcement drift
}

\author{
August, 2018
}

\begin{abstract}
$\underline{\text { Abstract }}$
Off-exchange trading, which tends to attract uninformed trades, accounts for about 35 percent of total trading volume today. Taking uninformed trades off exchanges harms liquidity but improves price discovery, indicated by a decline in intraday price inefficiency (deviation of price changes from a random walk). We examine whether it also decreases an accounting inefficiency: investor underreaction to quarterly earnings news. Our results, based on investigation of a large panel of US firms and a natural experiment created by the SEC's Tick Size Pilot program, suggest the opposite conclusion: off-exchange trading increases underreaction to earnings news. The negative effects of off-exchange trading on liquidity (less depth and wider spreads) likely increase arbitrage costs, thereby reducing arbitrage activity that partially corrects underreaction. We find that the positive relation between off-exchange trading and underreaction remains strong even when we control for a host of observable arbitrage cost measures. Levels of off-exchange trading appear to serve as a useful proxy for hard-to-measure arbitrage costs.
\end{abstract}

Keywords: Off-exchange trading; Post-earnings-announcement-drift; Limits to arbitrage; Liquidity; Price discovery; Price efficiency.

Online appendix:

https://drive.google.com/file/d/1weM_Ic1qNoT46JuvWOy1BRdDKxt_4hCJ/view?usp=shari ng 


\section{Off-exchange trading and post earnings announcement drift}

\section{Introduction}

Off-exchange trading (OFFEXCH) has increased over the past 20 years and now accounts for about 35 percent of total U.S. trading volume. Unlike "lit" exchanges, OFFEXCH is referred to as dark trading because investors are unaware of submitted orders until executed. For example, buy and sell orders sent to crossing networks are not visible to market participants; if matched they are recorded on exchanges, and unmatched orders are returned. As explained below, uninformed trades either gravitate toward or are channeled to dark venues (e.g. Menkveld, et al. 2017). Liquidity providers on exchanges then face higher odds of trading against private information, and liquidity declines — indicated by wider bid/ask spreads and less depth of unfilled limit orders (Hendershott and Mendelson, 2000; Zhu, 2014). Regulators express concerns about elevated levels of OFFEXCH; e.g., Mary Jo White (former SEC Chairman) suggests it may have reached a level that "risks seriously undermining the quality of price discovery provided by lit venues." However, empirical evidence suggests that $\mathrm{OFFEXCH}$ is associated with a decline, not an increase, in intraday price inefficiency (O'Hara and Ye 2011, Comerton-Forde et al. 2017, and Farley et al. 2018), where inefficiency is typically measured as deviation of price changes from a random walk (Lo and MacKinlay, 1988). ${ }^{1}$ This negative relation is consistent with the theory in Zhu (2014): removing uninformed trades off exchanges increases the signal-to-noise ratio of stock prices.

We investigate whether this negative relation extends to post earnings announcement drift (PEAD), an accounting-based inefficiency characterized as investor underreaction to reported earnings. Regulators' concerns about the impact of OFFEXCH on price discovery should be heightened for PEAD. Underreaction to earnings news has been shown to persist for up to three

1 While results from the handful of studies that investigate OFFEXCH and intraday inefficiency vary with the periods and markets sampled, only one study of U.S. data (Hatheway et al. 2017) finds a positive relation. 
quarters (e.g., Bernard and Thomas, 1989), far longer than the transitory intraday effects mentioned above. Also, whereas intraday inefficiency refers to private information, PEAD refers to publicly-announced earnings, a disclosure that is important to regulators.

A review first of how uninformed (informed) orders are segmented to dark venues (lit exchanges). Segmentation occurs for different reasons for institutional and retail orders. Institutional orders sent to dark pools benefit from price improvement at the expense of immediacy. Price improvement occurs because buys/sells are filled within the spread, but immediacy is compromised because execution is not guaranteed. Unlike uninformed trades that are patient and value price improvement over immediacy, informed trades value the immediacy offered by exchanges (e.g., Menkveld et al. 2017). Moreover, they are less likely to be matched on dark venues because they are positively correlated and likely to accumulate on the same "heavy" side of the market, unlike uninformed orders that are more evenly distributed (Zhu 2014).

Turning to retail orders, segmentation is an outcome of "cream-skimming," not investor choice. Almost all marketable orders received by brokers from individual investors are either purchased by unaffiliated OTC market makers or routed to an affiliated OTC market maker for execution (Battalio et al. 2016; SEC, 2010). OTC market makers internalize uninformed orders, and route to exchanges any orders they suspect are informed (e.g., Easley et al. 1996).

Next, a review of PEAD. Prior research suggests it reflects the net effect of two types of trades. First, noise traders do not appreciate fully the positive autocorrelation in seasonallydifferenced quarterly earnings (e.g., Bernard and Thomas, 1990), causing prices to underreact. Second, arbitrageurs trade in the direction of earnings news, to profit from this mispricing, but their incentives to do so decline as mispricing drops to levels corresponding to various arbitrage costs they face (Lee and So, 2015). If diverting uninformed trades to dark venues decreases 
intraday price inefficiency because prices better reflect the signal value of informed trades, it should also decrease PEAD by increasing the signal-value of arbitrageurs' trades.

There are fundamental differences, however, between the two inefficiencies that might cause their relations with OFFEXCH to differ. First, intraday inefficiency refers mainly to prices aggregating short-horizon, private information (e.g., information reflected in order flow), whereas PEAD reflects public information about longer-horizon firm performance. Second, intraday inefficiency is generally associated with overreaction (e.g. Heston, Korajczyk, and Sadka 2010; Tetlock 2010), but PEAD refers to underreaction. Finally, the negative effect of OFFEXCH on liquidity might be more important for PEAD than it is for intraday inefficiency, because liquidity affects the arbitrage costs that appear to be more relevant for PEAD.

Our main sample, which is more comprehensive than those considered so far as it includes all US firms with daily TAQ data from 2009 to 2017, yields the following descriptive findings. First, average OFFEXCH increases from about 25 percent of overall trading to about 35 percent over our sample period. Notwithstanding this increase over time, OFFEXCH is relatively sticky: it exhibits little within-firm variation within and across quarters. Second, OFFEXCH is related in the cross-section to arbitrage cost proxies from prior work: It varies positively with idiosyncratic return volatility (Mendenhall, 2004), and varies negatively with market capitalization (Foster, Olsen, and Shevlin, 1984) and liquidity measured by intraday effective spread and depth at national best bid and ask prices (NBBO) (Ng et al. 2008).

We first confirm that OFFEXCH is negatively related to intraday inefficiency, using our main sample and a natural experiment created by the SEC's Tick Size Pilot Program of 2016. We do so because prior results are based on less comprehensive/representative samples. ${ }^{2}$ We follow

2 Most studies are based on relatively short windows, possibly because of the large volume of intra-day transactions that need to be analyzed. For example, Farley et al. (2018) examine just the 20 days on either side of 
the approach used earlier, and use variance ratios - measures of the extent to which price changes deviate from a random walk - to describe intraday inefficiency. The natural experiment alleviates concerns that our main sample results are affected by endogeneity. We estimate difference-indifference regressions on two groups of small capitalization stocks over the one-year period before and after the change imposed by the SEC program. The incentive to trade off exchanges declines substantially for one group (treatment) but increases for the other (control). ${ }^{3}$ Our results are unequivocal: Both the main sample and natural experiment confirm that the relation between OFFEXCH and intraday inefficiency is strongly negative.

In sharp contrast to this robust, negative relation observed between OFFEXCH and intraday inefficiency, we find that OFFEXCH exhibits a statistically and economically significant positive relation with PEAD for our main sample. To illustrate magnitudes of underreaction, a hedge portfolio that invests long (short) in the quintile with the best (worst) earnings news generates close to zero returns over the next quarter for the lowest OFFEXCH quintile but earns almost 8 percent for the highest quintile. Whereas the negative effect of liquidity associated with OFFEXCH is less important for intraday inefficiency, relative to the signal-to-noise benefit, it appears to be more important for PEAD. Reduced liquidity—wider spreads and less depth—raises the costs faced by arbitrageurs (e.g., Bhushan 1994, Ng et al. 2008, and Chordia et al. 2009), leading to less arbitrage activity and more underreaction.

As with our investigation of intraday inefficiency, we turn to the natural experiment created by the SEC program to supplement our main sample results on PEAD. We find a similar, significant positive relation when earnings news is measured as announcement returns, but the

the change associated with the natural experiment. Also, some studies relate to non-US markets and might be less representative of US markets because of different trading and regulatory environments.

3 While OFFEXCH reduces sharply for the treatment group, we are unable to control for other actions that affected firms and investors in those firms might take in response to limited access to dark venues. 
relation is not significant when earnings news is measured as forecast errors. This latter result is due to the underlying relation between PEAD and forecast errors being insignificant in our Tick Size sample, leaving little room for a significant interaction effect. Finding that PEAD is only weakly related to forecast error, but strongly related to announcement returns for this sample is in line with the emerging consensus (e.g., Milian 2013) that forecast errors are a noisy measure of earnings news. ${ }^{4}$

We also find that the positive relation between OFFEXCH and PEAD declines as we introduce arbitrage cost proxies. This result confirms the prevailing view (e.g., Bhushan 1994; $\mathrm{Ng}$ et al. 2008; Chordia et al. 2009) that observed PEAD reflects limits to arbitrage: underreaction by noise traders is corrected to the point where mispricing equals arbitrage costs. We find, however, that a substantial fraction of this relation remains even when we include a host of observable arbitrage cost measures. This incremental ability to explain underreaction suggests two possibilities: the observable arbitrage cost measures we use are associated with measurement error, and OFFEXCH proxies for unobservable arbitrage costs, such as the costs of arbitrage capital (Lee and So, 2015).

This paper contributes to two literatures. First, we extend the PEAD literature by showing that PEAD increases with off-exchange trading, a source of variation in PEAD that has remained unexplored despite the increased importance of trading on dark venues. We investigate a comprehensive panel of US firms since 2009 as well as a natural experiment created by the SEC's Tick Size Pilot program to confirm that off-exchange trading harms liquidity, and this negative impact on liquidity appears to increase PEAD because it increases arbitrage costs. We also offer

4 Perhaps forecast errors are subject to increasing manipulation, and levels of manipulation vary across firms. For example, Cheong and Thomas (2017) show systematic cross-sectional variation in mean forecast errors, generated by differential forecast guidance designed to generate positive forecast errors. 
an important proxy for arbitrage costs—levels of OFFEXCH—for researchers investigating pricing anomalies. It appears to explain considerable variation in PEAD even after we include a host of known arbitrage cost proxies. Second, we contribute to the general OFFEXCH literature by showing that it affects different pricing inefficiencies differently: Whereas OFFEXCH mitigates intraday inefficiency, because of an associated increase in the signal-to-noise ratio of prices, it exacerbates earnings-based mispricing. As discussed above, this result highlights the negative liquidity impact of OFFEXCH and the role played by arbitrageurs. Given the increasing importance of off-exchange trading in capital markets, this finding calls for more research on the impact of off-exchange trading around accounting disclosures, to supplement the insights garnered so far from studying its impact on different aspects of market quality. ${ }^{5}$

The remainder of this paper is laid out as follows. Section 2 details the institutional setting, describes the prior literature and develops our empirical prediction. Section 3 provides details of our sample selection process and some descriptive statistics. Section 4 presents our main results. Section 5 contains robustness checks, and Section 6 concludes.

\section{Institutional setting, prior literature, and predictions.}

\subsection{Equity market structure}

As accounting audiences may be less familiar with recent innovations in equity markets, we take this opportunity to describe different trading venues and review prior research linking institutional features of dark venues to liquidity and price discovery (intraday inefficiency).

The stock market in the U.S. offers both lit and dark trading venues. Lit venues—primarily registered exchanges - provide both pre- and post-trade transparency. Prices and trading interests

5 We note some early interest among accounting researchers in off-exchange trading. For example, Gkougkousi and Landsman (2018) investigate variation in OFFEXCH around quarterly earnings announcements. 
are displayed prior to execution, and transaction details are publicly disseminated in real time. ${ }^{6}$ Registered exchanges are generally structured as electronic limit order book markets, where multiple buyers and sellers can trade against each other within the system. They offer nondiscriminatory access, and operate according to nondiscretionary rules and procedures. ${ }^{7}$

Dark venues, often called off-exchange, provide post-trade transparency but are pre-trade opaque: their best priced bids and offers are not required for inclusion in publicly distributed, consolidated quotation data. Transaction prices in dark venues are typically derived from or pegged to NBBO on exchanges. In addition, they are not subject to fair access requirements, and can thus prohibit or limit clients from accessing their services. The SEC (e.g., concept release from 2010) and the finance literature (e.g. Zhu 2014; Buti, Rindi, and Werner 2017) divide dark venues into four major groups, based on trading mechanisms employed.

(1) Crossing networks (e.g., ITG Posit). Customers in crossing networks, mainly buyside institutions, submit unpriced orders. At prescheduled times, the organizing agency brokerswho do not trade on their own account — match buy and sell orders at "intermediate" prices derived from lit venues, such as the midpoint between national best bid and offer prices (NBBO) and volume-weighted average price (VWAP). Imbalances in buy and sell orders remain unfilled. Crossing networks provide price improvement at the expense of immediacy, consistent with anecdotal evidence suggesting that they were initially designed for block trades (Kwan et al. 2015).

(2) Nondisplayed limit order book (e.g., GS Sigma X). Nondisplayed limit order books (LOB hereafter) are limit order books without pre-trade transparency. These nondisplayed LOBs are usually operated by banks or brokers, who also trade on their own accounts. Customers

\footnotetext{
Exchanges do permit hidden limit orders, which are not pre-trade transparent.

7 Electronic communication networks (ECN) are similar to exchanges, except they do not provide all services provided by exchanges, such as stock listings. As of March 2012, there is only one significant ECN-LavaFlowwhich accounts for around 2 percent of the consolidated share volume (CFA Institute, 2012).
} 
are again mainly buy-side institutions who can submit market, limit, or pegged orders ${ }^{8}$. Execution prices are derived from the prices of submitted orders, typically bounded by NBBO on exchanges, on a continuous basis. These venues provide more immediacy than crossing networks, but offer less price improvement.

(3) PING destinations (e.g., Knight Link). PING venues are fast electronic market makers that immediately accept or reject incoming orders. These PING venues are usually operated by over-the-counter (OTC) market makers, who trade as principals. Their main customers are buy-side institutions who submit immediate or cancel (IOC) orders. Execution prices are determined by market makers. PING venues also provide more immediacy than crossing networks, but offer less price improvement.

(4) Broker/dealer internalization (e.g., Citadel securities). Broker/dealer internalization refers to OTC market makers purchasing retail order flow from brokerage firms and executing it internally. Battalio, Corwin, and Jennings (2016) show that almost all retail marketable (i.e. market or marketable limit) orders and half of all retail limit orders are routed by retail brokerages directly to OTC wholesale dealers. Knowledge of the identities of the retail orders allows OTC market makers to internalize uninformed retail flow and route potentially informed flow to exchanges. When internalizing retail orders, OTC market makers often provide retail investors with little (e.g. \$0.001) or no price improvement compared with NBBO.

Using proprietary data from NASDAQ in 2010-2011, Kwan et al. (2015) and Menkveld et al. (2017) estimate that the fraction of overall trading volume executed on crossing networks, nondisplayed LOBs, PING venues, and broker/dealer internalization is around 2.5 percent,

8 Pegged orders are limit orders with the limit price set relative to an observable market price, such as the bid, the offer, or the midpoint. As the market moves, the limit price of a pegged order moves accordingly. See Zhu (2014) online appendix. 
between 7.8 to 9.8 percent, between 4.5 to 7.8 percent, and between 5.7 to 12.9 percent, respectively. The four dark venues are subject to different regulatory oversight. Crossing networks and nondisplayed LOBs operate as alternative trading systems (ATS) and need to comply with Regulation ATS, while PING venues and retail internalization are registered as non-ATS market makers subject to broker-dealer regulations.

\subsection{The post-earnings announcement drift (PEAD)}

Price drifts after earnings announcements have been documented first for annual earnings (Ball and Brown, 1968) and later for quarterly earnings (Joy et al. 1977). Drifts after quarterly earnings have received more attention because their magnitudes are larger. Researchers have considered various explanations for apparent underreaction by investors to earnings news at announcements, followed by a subsequent correction. The emerging consensus is that observed underreaction at announcement is the net effect of trades by two type of investors: noise traders and arbitrageurs. Mispricing originates because noise traders ignore positive autocorrelation, or persistence, in seasonally-differenced earnings. Arbitrageurs profit from this mispricing by trading in the direction of earnings news and move prices toward fundamental values. The incentives for arbitrageurs to trade decline, however, as the gap between traded and efficient prices approaches the total costs of arbitrage. These costs include a variety of costs beyond direct trading costs, such as price impact and access to arbitrage capital (e.g., Lee and So, 2015). Subsequent correction occurs when noise traders receive signals about the predictable portion of next quarter's earnings that reflect underlying persistence.

Variation in drifts, or net underreaction at earnings announcements, is shown to be related to proxies for both effects mentioned above. Drifts vary with three proxies for earnings persistence that explain "original" mispricing, before arbitrageurs intervene: earnings volatility (EVOL), an indicator variable for the fourth quarter (FQ4), and an indicator variable for negative earnings 
(LOSS). Persistence is expected to be lower for high EVOL (Cao and Narayanamoorthy, 2012), for fourth fiscal quarters (Rangan and Sloan 1998), and for firms reporting losses (Narayanamoorthy 2006). Drifts also vary with liquidity measures that proxy for limits to arbitrage (e.g., Bhushan 1996; Ng et al., 2008; Chordia et al., 2009): they decline as transaction costs fall and arbitrage activity increases (Ke and Ramalingagowda, 2005). Relatedly, Johnson and Schwartz (2000), Richardson et al. (2010), and Chordia et al. (2014) find that mispricing related to drifts has declined in recent years, especially among liquid stocks. In fact, there are indications that arbitrage activity has become so aggressive that prices overshoot their efficient levels in some cases (Milian 2015).

\subsection{Links between off-exchange trading and price inefficiency}

\subsubsection{Segmentation of uninformed order flow on dark venues}

The trading mechanisms and regulatory oversight of dark venues discussed above cause increased concentration of informed trades on lit exchanges, because uninformed (informed) trades shift toward dark (lit) venues. These shifts occur for different reasons for institutional versus retail orders. The vast majority of institutional orders are processed using computerized algorithms trading off immediacy of execution against execution costs. Dark pools, such as crossing networks, are more attractive for patient and uninformed liquidity trades that value price improvement more than immediacy. In contrast, informed trades value immediacy. Moreover, they tend to crowd on the same, heavy side of the market, resulting in higher execution risk in dark pools, unlike uninformed trades that are distributed more evenly. Consequently, exchanges are more attractive for informed trades (e.g. e.g. Zhu 2014; Menkveld et al., 2017).

As discussed earlier, almost all retail marketable (i.e. market or marketable limit) orders 
are routed by retail brokerages directly to OTC wholesale dealers. ${ }^{9}$ Upon receipt of order flow, the wholesale market maker typically fills orders internally against its own account or-if an order is likely informed - routes it for execution to other wholesalers, other internalization pools, other market centers, or exchanges. Knowledge of customer identity allows market makers to separate informed orders from uninformed ones, to profit on retail orders that are on the "wrong" side of the market (i.e., against the direction of expected market movements in the short-term), and route remaining orders to other market centers. The academic literature (e.g., Chordia and Subrahmanyam 1995 and Easley, Keifer, and O'Hara 1996) provides evidence consistent with this practice of "cream skimming". Consequently, order flow eventually reaching exchanges is filtered: there are fewer opportunities for displayed liquidity providers - those posting limit orders on exchanges - to trade against retail order flow.

Existing empirical evidence is consistent with off-exchange trades containing less information than on-exchange trades. Jiang et al. (2012) and Hatheway et al. (2017) show that offexchange trades have lower information ratio, defined as information share (Hasbrouck, 1995) divided by volume share, lower bid-ask spread, and lower price impact than on-exchange trades. Comerton-Forde and Putnins (2015) reach a similar conclusion on the informativeness of offexchange trades using an Australian sample. Reed et al. (2018) show that short sellers, which are typically informed, trade more on exchanges than in dark pools. To be sure, not all informed trades are expected to migrate to exchanges (e.g., Nimalendran and Ray, 2014).

\subsubsection{Impact of segmentation on intraday inefficiency and PEAD}

Theory suggests that accumulation of relatively more informed (uninformed) trades on lit exchanges (dark venues) should increase the signal-to-noise ratio in stock prices but reduce market

9 Many wholesalers have standing payment-for-order flow agreements with retail brokerages, typically paying 0.1 cent per share or less (SEC 2010). 
liquidity (e.g., Hendershott and Mendelson, 2000; Zhu, 2014). The former effect arises because OFFEXCH increases the on-exchange proportion of informed to uninformed trades. The latter effect is a consequence of the associated increase in adverse selection risk for market makers on exchanges. Market makers raise bid-ask spreads to recoup anticipated losses from providing liquidity to informed trades (e.g. Chakravarty and Sarkar, 2002; Dutta and Madhavan, 1997; Easley et al. 1996; Kluger and Wyatt, 2002), and the wider spread imposes higher transaction costs on both on-exchange and off-exchange trades.

Theory also suggests that price discovery, or intraday efficiency, should improve directly with increased signal-to-noise ratio, but could decline indirectly because of reduced liquidity. The direct effect of increased signal-to-noise ratio is because market makers respond more quickly to the information in order flows (e.g., Zhu 2014). The indirect effect of liquidity arises because it reduces traders' incentives to acquire private information (e.g., Admati and Pfleiderer, 1988; Kyle, 1989).

The evidence based on US data, albeit limited in terms of the number of studies conducted as well as sample sizes investigated, is generally consistent with the direct effects of increased signal-to-noise ratios: intraday inefficiency is negatively related to OFFEXCH..${ }^{10} \mathrm{O}$ 'Hara and Ye (2011) and Farley et al. (2018) find a negative relation for a panel and the natural experiment created by the SEC tick size pilot program, respectively. The results in Haslag and Rigggenberg (2016) and Comerton-Forde et al. (2017) can also be interpreted as being consistent with this negative relation. Hatheway et al. (2017), which is based on a sample of 116 firms over the first quarter of 2011, is the only study documenting a positive relation for U.S. firms.

Turning from intraday inefficiency to PEAD, there is basis for predicting both a negative

10 Evidence on non-US markets is mixed. Foley and Putnins (2016) find a positive relation for Canadian data, but Comerton-Forde and Putnins (2015) document a negative relation for Australian data. 
and positive relation between OFFEXCH and PEAD. The negative relation arises simply by extending the beneficial effect of increased signal-to-noise ratio associated with intraday inefficiency. Market makers respond more quickly to arbitrageurs' orders and adjust prices in the direction of earnings news. As a result, prices at the end of day +1 (where day 0 is the earnings announcement date), when we begin the holding period for PEAD, should underreact less.

The basis for a positive relation is that reduced liquidity increases arbitrage costs, which then increase residual underreaction to earnings news. Whereas the lower liquidity associated with OFFEXCH has only an indirect effect on intraday inefficiency, it is likely to have a stronger, more direct effect on PEAD. Lower liquidity, evidenced as higher bid/ask spreads and less depth of unfilled limit orders at bid and ask prices, increases costs faced by arbitrageurs. The incentives to engage in arbitrage decline accordingly, along with an increase in the limits beyond which arbitrage profits exceed arbitrage costs (e.g., Ng et al., 2008; Chordia et al. 2009).

\section{Sample and descriptive results}

\subsection{Sample selection}

While off-exchange trading has existed for a few decades, data availability has hampered meaningful large-sample analyses. Prior to 2007, all off-exchange trades were reported to exchanges but combined with on-exchange trades when recorded on the consolidated tape. ${ }^{11}$ After March 5, 2007, Rule 601(b) of Regulation NMS under the Exchange Act requires OTC trades, including trades executed by ATSs, to be reported to the consolidated trade streams through one of the trade reporting facilities ("TRFs") operated by FINRA on behalf of exchanges, or through

11 As a result, earlier studies of off-exchange trading such as broker/dealer internalization are limited to specific settings or proprietary data and often reach conflicting conclusions (e.g. Battalio 1997; Battalio, Greene, and Jennings 1998; Chung, Chuwonganant, and McCormick 2004). 
FINRA's ADF. ${ }^{12}$ However, TRF reports before November, 2008 include trades on two large ECNs - BATS and DirectEdge - that should be viewed as similar to lit exchanges. Our sample begins in 2009 after which dark trading is identified relatively cleanly. Note that the identity of the particular dark pool or broker-dealer that executes the trade remains undisclosed.

As described in Table 1, Panel A our main sample begins with Compustat/CRSP firmquarters with earnings announcement dates that are within three months of quarter-end and at least 30 trading days after the prior announcement. We exclude financial firms and require non-missing values of two earnings surprise measures: 2-day earnings announcement window returns (EARET) and analyst forecast error (FE). (The Appendix provides details for all variables.) We exclude observations with share price at fiscal quarter-end below $\$ 1$, and require non-missing values for two measures of arbitrage risk that have been shown to explain cross-sectional variation in mispricing: idiosyncratic return volatility (Mendenhall, 2004) and intraday mid-quote return variance. We also require non-missing values for the three factors that proxy for persistence of earnings news: earnings volatility (EVOL), and indicator variables for fiscal fourth quarters (FQ4) and negative GAAP earnings (LOSS). Finally, we require non-missing values for our main variable of interest, OFFEXCH: the average during the pre-announcement window of the daily fraction of total shares traded that is executed off stock exchanges. We do not use OFFEXCH during the earnings announcement window as it may be mechanically related to earnings news. ${ }^{13}$ Our final panel includes 74,190 firm-quarters from 2009Q1 to 2017Q2.

Following prior studies on off-exchange trades (e.g. Hatheway et al. 2017; Weaver, 2011), we collect trades during regular trading hours (9:30 AM to 4:00 PM) and require positive values

12 Securities Exchange Act Release No. 54084 (June 30, 2006), 71 FR 38935 (July 10, 2006) (File No. SR-NASD2005-087) establishes rules for the reporting of off-exchange transactions through the new TRFs.

13 Untabulated results confirm that the increase in off-exchange trading at announcements, relative to preannouncement levels, is related to the earnings news magnitudes. 
for trade price and shares traded. ${ }^{14}$ For each trade, Daily TAQ (DTAQ) data separates trades executed on stock exchanges (TAQ EX $\neq$ 'D') from those executed off exchanges (TAQ EX $=$ 'D'). ${ }^{15}$ We estimate OFFEXCH over the pre-announcement period that begins on day +2 of quarter q-1 and ends on day -1 of quarter q. Figure 1 , which shows cross-sectional average OFFEXCH for fiscal quarters that end in different calendar quarters, indicates a slight upward trend: mean OFFEXCH increases from about 25 percent in 2009 to 35 percent in 2017.

To supplement our analyses based on the main sample, we leverage the natural experiment created by the SEC that offers the opportunity to compare a treatment group which experiences an exogenous decline in off-exchange trading with an otherwise similar control group that experiences an increase. Briefly, the SEC's Tick Size Pilot Program is a data-driven experiment to study the impact of widening minimum increments (tick sizes) — for both quotes and tradeson trading and liquidity for small capitalization stocks. ${ }^{16}$ Prior to this intervention, implemented in October, 2016, the tick size for both quotes and trades is $\$ 0.01$. After the intervention, four groups of randomly selected securities face different combinations of minimum quote and trade tick sizes, each set at either $\$ 0.01$ or $\$ 0.05$. In addition, one of the groups faces a "trade-at" prohibition: nondisplayed orders cannot be executed within or at quoted bid/ask prices. In essence, non-displayed orders can only be executed outside quoted bid/ask prices.

This group, which is subject to the quote, trade, and trade-at rules, is our treatment group, whereas a second group that is subject to just the minimum $\$ 0.05$ quote rule is our control group. These groups are referred to by the SEC as test group 3 and test group 1, respectively (SEC 2015).

14 About 10 percent of overall trading occurs after hours, mostly on dark venues. We exclude those trades because they are likely a mix of trades that would have been sent to lit and dark venues if both options were available.

15 We exclude intermarket sweep order (ISO) trades when counting off-exchange trades, as these orders are most likely executed in non-exchange electronic communication networks (ECN) such as LavaFlow instead of dark pools or broker/dealer internalization.

16 Details of the Tick Size Pilot Program are available at http://www.finra.org/industry/tick-size-pilot-program. 
Increasing the minimum quoted bid/ask spread for the control group drives more trades to dark venues to avail of the increased opportunities for price improvement, achieved by executing trades within the spread. In contrast, OFFEXCH should decline for the treatment group because most trades on dark venues must now be traded outside the quoted spread. ${ }^{17}$

While we view a comparison of our treatment and control groups as reflecting the impact of an exogenous change in OFFEXCH, we recognize that affected firms and investors might respond to the change in OFFEXCH in ways that also affect liquidity, intraday inefficiency, and PEAD. ${ }^{18}$ As a result, even though we ascribe any observed differences in these response variables to changes in OFFEXCH levels, we cannot rule out the possibility that they are due partially to other responses taken by firms and investors.

The results in Figure 2 describe daily levels of OFFEXCH for the treatment and control groups for one-year windows on either side of the October, 2016 implementation of the pilot program. ${ }^{19}$ OFFEXCH for the control group increases from about 35 percent to about 40 percent, consistent with the predicted increase in order flow to dark venues, seeking to gain price improvement. In contrast, OFFEXCH declines sharply for the treatment group to about 25 percent. Again, consistent with predictions, order flow returns to exchanges when trades are required to be executed outside quoted spreads. A difference-in-difference design that compares the treatment and control groups over the one year windows before and after the change allows us to infer the impact of OFFEXCH on liquidity, intraday inefficiency, and PEAD.

17 Exemptions to the trade and trade-at rules are allowed for midpoint executions, retail investor executions with a minimum price improvement of $\$ 0.005$, and negotiated trades.

18 For example, Hansen et al. (2017) and Comerton-Forde et al. (2017) show that trading on exchanges with inverted fee structures - charging fees for posting limit orders but providing rebates for sending marketable orders - increases for the treatment group.

19 The sharp, periodic declines for OFFEXCH noted in Figure 4-which coincide with the third Fridays of March, June, September, and December, when contracts for futures/options for stocks and stock indexes expire-are due to sharp increases in on-exchange trading ( 32 percent for our sample). Off-exchange trading remains unchanged. 
We follow Rindi and Werner (2017) to construct the Tick Size Pilot sample (see Panel B of Table 1). After requiring data necessary to calculate intraday liquidity measures, 334 control firms and 328 treatment firms remain. Daily data for these two groups generate measures of intraday inefficiency, and quarterly data obtained for $2,426(2,154)$ firm-quarters for the control (treatment) group generate measure of PEAD.

\subsection{Descriptive statistics}

The results reported in Table 2, Panel A provide statistics for the distributions of key variables. PEAD, the delayed price response per unit of earnings news, is missing as it is not estimated at the firm-quarter level. Instead, it is captured by the coefficient on earnings news in a regression predicting future size-adjusted returns $\left(\mathrm{SARET}_{\mathrm{q}+1}\right)$. Returns are cumulated from the day after the current earnings announcement window (day +2 for quarter $q$ ) to the end of the earnings announcement window for the next quarter (day +1 for quarter $q+1$ ). Day 0 is the earlier of the announcement dates recorded in Compustat and IBES. Size-adjustment is performed by subtracting returns earned over the same window by firms in the same market capitalization decile. $^{20}$

The two earnings news or surprise (SUR) measures are computed as follows. EARET is the size-adjusted return over the 2-day earnings announcement window that includes days 0 and +1 for quarter q. Size adjustment for returns is more important for EARET than for $\mathrm{SARET}_{\mathrm{q}+1}$ because announcement window returns are on average positive (e.g., Cohen et al. 2007) and vary with firm size (market capitalization). FE is actual earnings per share (EPS) minus the most recent consensus of analyst forecasts, both based on IBES data, scaled by price at prior quarter-end.

Table 2, Panel B provides pair-wise correlations among key variables, with Pearson

20 Market capitalization deciles are computed as of the most recent calendar year-end before the earnings announcement. 
(Spearman) correlations reported above (below) the main diagonal. In general, the correlations are significant and consistent between Pearson and Spearman correlations. The relations are also generally consistent with those documented in prior research. The positive correlations between SARET $_{\mathrm{q}+1}$ and the two earnings news measures-FE and EARET-confirm underreaction to earnings news in our main sample. Consistent with OFFEXCH harming liquidity, it is strongly positively related to effective spread (ESPD) and negatively related to depth (DEP).

\section{Results}

\subsection{Confirm that OFFEXCH is negatively related to intraday inefficiency}

Before investigating the relation between OFFEXCH and PEAD, we first confirm that OFFEXCH is negatively related to intraday inefficiency. We follow prior research (e.g., Lo and MacKinlay 1988) and measure intraday inefficiency as the deviation of mid-quote returns from random walks, using daily variance ratios (VRATIO) over three pairs of intervals. Random walks are indicated if the return variance computed over intervals of $k^{*} l$ minutes is $k$ times the return variance computed over intervals of $l$ minutes. The three pairs of intervals we use are: 5 and 1 minute $(k=5, l=1) ; 15$ and 5 minutes $(k=3, l=5)$; and 30 and 15 minutes $(k=2, l=15)$.Variance ratios equal the absolute value of $\left(\sigma_{k l}^{2} / k^{*} \sigma_{l}^{2}\right.$ minus 1$)$, where $\sigma^{2}$ refers to the return variance over the corresponding interval. VRATIO equals 0 for random walks, and larger values of VRATIO indicate greater intraday inefficiency (under or overreaction).

The results in Table 3, Panel A confirm the negative relation between VRATIO and OFFEXCH for our main sample. The first three columns describe the simple relation between the two variables, and the next three columns include controls for various factors that are likely to affect variance ratios. All independent variables are ranked into deciles by calendar quarter, and assigned values between -0.5 (lowest decile) and 0.5 (highest decile). The coefficients thus indicate 
the change in value of the dependent variable as the independent variable increases from the lowest to the highest decile. The coefficients are negative in all columns, and very significant in all columns except the first. Importantly, they are negative and very significant in columns (4) to (6) when we include controls.

We repeat the analysis on data generated by the natural experiment, which represents an arguably exogenous change in OFFEXCH. We consider just the TREAT*POST interaction for the difference-in-difference regressions, as we include firm and day fixed effects. The first column in Panel B of Table 3 confirms the results depicted in Figure 2: OFFEXCH for the treatment group is substantially lower (about 14 percent) than that for the control group in the post period. The remaining columns in Panel B confirm that the lower levels of OFFEXCH for the treatment group result in higher market liquidity, due to a decline in adverse selection risk when uninformed trades return to exchanges. The two liquidity measures we use are: effective spread (ESPD) and depth (DEP). The results confirm that the treatment group, which faces a decline in OFFEXCH, also experiences higher liquidity, evidenced by smaller spreads and greater depth. These results are consistent with those in Rindi and Werner (2017) and Rosenblatt Securities (2018).

The results in Panel $\mathrm{C}$ of Table 3 confirm that the negative relation between VRATIO and OFFEXCH observed for our main sample is again observed for the natural experiment. The coefficient on TREAT*POST is positive and significant for all three intervals. A decline in OFFEXCH results in higher variance ratios, implying increased intraday inefficiency. We believe the stronger results we report in Table 3, relative to prior research, are due to the larger samples we consider. Our panel includes more firms and years than that in prior research, and we consider a wider window around the natural experiment than the 20 days examined in Farley et al. (2018).

\subsection{Relation between OFFEXCH and PEAD in the main sample}

Having confirmed the negative relation between OFFEXCH and intraday inefficiency, we 
investigate whether a similar negative relation exists between OFFEXCH and PEAD. To do so, we first estimate regressions of $\mathrm{SARET}_{\mathrm{q}+1}$ on earnings news (EARET and FE) to identify magnitudes of drift for our main sample. We then check whether that drift varies with OFFEXCH by interacting earnings news with OFFEXCH. The discussion in Section 2 suggests that the relative importance of the two effects of OFFEXCH—improved signal-to-noise ratio and reduced liquidity—determines the sign of this interaction.

Figure 3 offers preliminary findings. We report mean values of $\mathrm{SARET}_{\mathrm{q}+1}$ for the highest (Q5) and lowest (Q1) quintiles of earnings news, as well as hedge returns (Q5 - Q1), or the difference between the returns for the highest and lowest quintiles. Means for these three measures of future returns are reported separately for each quintile of OFFEXCH. Panels A and B refer to earnings news measured as EARET and FE, respectively. We find that future returns after good news (Q5) generally increase with OFFEXCH and that future returns after bad news (Q1) generally decrease with OFFEXCH. As a result, hedge returns increase significantly with OFFEXCH. In Panel A, hedge returns are close to zero for the first three quintiles of OFFEXCH and increase to about 8 percent for the top OFFEXCH quintile. In Panel B, hedge returns based on FE are again close to zero for the first three quintiles of OFFEXCH and increase to about 5 percent for the top OFFEXCH quintile. Observing a strong positive correlation between OFFEXCH and underreaction suggests that the negative liquidity impact of OFFEXCH is more important than the improved signal-to-noise ratio. Lower liquidity increases arbitrage costs resulting in more residual underreaction to earnings news.

Table 4 provides regression results, where Panels A and B refer to earnings news measured as announcement returns (EARET) and forecast errors (FE), respectively. Again, all independent variables are sorted into deciles each calendar quarter and assigned values between -0.5 and 0.5 , 
so that the coefficient can be interpreted as the hedge return over the next quarter from going long (short) in the highest (lowest) decile of that variable. Note that the coefficients, adjusted $\mathrm{R}^{2}$, and sample size reported in Table 4 regressions are based on pooled regressions with standard errors clustered by firms and by quarters (Gow, Oramazabal, Taylor 2010). All regressions include controls for four factors that have been shown to predict returns: beta risk (BETA), market capitalization (SIZE), book-to-market ratio (BTM), and momentum based on returns over the prior 11 months (MOM11).

The coefficient of 0.026 on EARET in Column (1) in Panel A suggests that a long/short position in extreme deciles of earnings news generates a hedge return of 2.6 percent, after controlling for BETA, SIZE, BTM, and MOM11. Introducing the interaction between EARET and OFFEXCH in column (2) provides results similar to those in Figure 3: The coefficient estimate suggests that the difference between the hedge returns for the top and bottom OFFEXCH deciles is 9.7 percent. Because Table 4 is based on deciles, rather than the quintiles used in Figure 3, it is associated with slightly larger hedge returns. The coefficient on the main effect of OFFEXCH is insignificant, which suggests that returns are not affected by levels of off-exchange trading.

Figure 4, Panel A describes time-series variation in these two coefficients from Table 4, Panel A: EARET in column (1) and EARET*OFFEXCH in column (2). While there is variation across quarters for both coefficient estimates, the plots suggest two takeaways. The coefficient on EARET is positive in all but two quarters of our sample, which confirms that PEAD continues to exist in our more recent sample. More relevant to this study, the interaction between EARET and OFFEXCH is always positive. That is, in every quarter firms with higher levels of off-exchange trading are associated with more PEAD than firms with less off-exchange trading.

Column (3) in Table 4, Panel A includes the three variables that have been shown in prior 
research to explain cross-sectional variation in the autocorrelation in seasonally-differenced quarterly earnings that noise traders underreact to: an indicator variable for the presence of a loss (LOSS), an indicator variable for the fiscal fourth quarter (FQ4), and earnings volatility (EVOL). The significant negative interaction for FQ4 is consistent with the results in Rangan and Sloan (1998): drifts are lower after earnings announcements for the fourth quarter. The positive coefficients for the interaction terms with EVOL is inconsistent with the negative interaction observed in Cao and Narayanamoorthy (2012), and negative yet insignificant coefficients for the interaction terms with LOSS differ from the negative, significant coefficient in Narayanamoorthy (2006). We note, however, that those two prior studies are based on earnings news measured as forecast error, not EARET. As in column (2), none of the main effects are significant.

The corresponding results in Panel B of Figure 4 and Table 4 suggest similar inferences when earnings news is measured as forecast error. For brevity, we do not include coefficient estimates for controls and main effects. The coefficient on FE in column (1) is positive and significant confirming that PEAD exists in our sample period. The coefficient on FE*OFFEXCH in column (2) is positive and significant, indicating that PEAD increases with OFFEXCH. Variation over time in these two coefficients shown in Panel B of Figure 4 provides inferences similar to those in Panel A. And the coefficient FE*OFFEXCH remains positive and significant in column (3) when we include controls for the three factors that proxy for persistence in earnings news. One difference is that the coefficient on $\mathrm{FE}^{*} \mathrm{EVOL}$ is negative and significant, not positive as in Panel A, but consistent with the results in Cao and Narayanamoorthy (2012).

\subsection{Can liquidity measures explain variation in the relation between OFFEXCH and PEAD?}

If the positive relation observed between OFFEXCH and PEAD is due to the negative impact of OFFEXCH on liquidity, we expect this relation to become insignificant when we include controls for liquidity. Directly capturing the impact of liquidity on PEAD, which reflects the higher 
arbitrage costs that result in residual underreaction to earnings news, should eliminate any role for OFFEXCH. Columns (4) through (7) in both Panels of Table 4 describe the impact of sequentially introducing four measures of liquidity: Effective spread (ESPREAD); Depth (DEP); idiosyncratic volatility in daily returns over the prior year (IDVOL); and intraday mid-quote variance computed at one-minute intervals (VAR). We interact each liquidity measure with earnings news to control for its effect on PEAD, and also allow for a main effect to control for any relation between those measures and the level of future returns.

The main conclusion from this analysis is that while the relation between OFFEXCH and PEAD declines when liquidity controls are introduced, it remains substantial and highly significant. The coefficient on EARET*OFFEXCH in Panel A declines from over 9 percent to just below 6 percent, and the coefficient on FE* OFFEXCH in Panel B declines from over 6 percent to just below 4 percent. The liquidity measure that exhibits the most significant relation with PEAD is ESPD, as its interaction with earnings news remains significant in all specifications. Interactions with the remaining liquidity measures are statistically insignificant, but that lack of incremental significance may be due to multicollinearity, induced by the high correlations among the liquidity measures, noted in Table 2, Panel B.

Failing to eliminate the positive relation between OFFEXCH and PEAD suggests two possibilities that are not mutually exclusive. First, the specific variables we consider measure the underlying liquidity constructs with considerable error. Second, arbitrage costs include many other factors, beyond the costs created by lower liquidity. A fuller consideration of the various factors that affect arbitrage activity includes many other costs such as the costs of financing, hedging, and model error (e.g., Lee and So 2015). Regardless, observing that OFFEXCH plays an economically and statistically significant role in explaining PEAD suggests that levels of off-exchange trading 
serve as a useful proxy for hard-to-measure arbitrage costs.

\subsection{Results from the natural experiment created by the SEC's pilot project}

As with our study of the relation between OFFEXCH and intraday inefficiency, we turn to the natural experiment for a different perspective, in case endogeneity affects our main sample results. As the intervention introduced by the pilot project results in a sharp decline in OFFEXCH for the treatment group, relative to the control group, a comparison of PEAD before and after the intervention for the two groups describes the impact on PEAD of an exogenous decline in OFFEXCH. The results reported in Panel A of Table 5 are designed to confirm that PEAD is present in this limited sample, representing 662 small capitalization firms during the eight quarters surrounding October, 2016. We estimate a regression of returns over the next quarter $\left(\operatorname{SARET}_{\mathrm{q}^{+1}}\right)$ on our two earnings news measures (SUR), in the presence of controls for the four variables that explain levels of returns: BETA, SIZE, BTM, and MOM11. Our results suggest that PEAD is observed when earnings news is measured as announcement returns (EARET) but not when it is measured as forecast error (FE).

The analysis reported in Panel B investigates whether PEAD declines for the treatment group after the intervention introduced by the pilot program, relative to that for the control group. This difference is captured by the coefficient on SUR*TREAT*POST. We include firm and quarter fixed effects, interactions between earnings news and those fixed effects, as well as controls for the four factors that explain levels of returns. The main result from this analysis is that PEAD declines significantly for the treatment group when earnings news is measured as EARET. This finding is consistent with the positive relation between PEAD and OFFEXCH observed for the main sample. The coefficient on SUR*TREAT*POST is again not significant for FE. We suspect that this lack of significance arises because SUR is not significant for FE in Panel A. If PEAD is insignificant when earnings news is measured as forecast errors, it seems likely that variation in 
PEAD across deciles of OFFEXCH will also be insignificant.

\section{Robustness checks}

We conduct a number of analyses to investigate the robustness of our two main findings: (a) PEAD increases with OFFEXCH, and (b) this positive relation survives controls for a host of arbitrage cost measures. Given the volume of results obtained, we offer a summary discussion below and tabulate some key analyses in an Online Appendix.

\subsection{Contemporaneous price response to earnings news.}

One approach used in the prior literature to confirm underreaction (e.g., Ng et al., 2008) is to determine if the contemporaneous response to earnings news (earnings response coefficient or ERC) varies negatively with the magnitude of news. For ERC regressions, we are limited to just one measure of earnings news (FE), as the other measure (EARET) is now the dependent variable. Table A1 describes variation in ERC across deciles of OFFEXCH using regression specifications similar to those in Panel B of Table 4. Results in column (1) of Table A1 confirm that ERC is clearly positive, even in the presence of controls for factors that explain variation in announcement returns (such as BETA and SIZE). More important, the results in column (2) are consistent with underreaction increasing with OFFEXCH, as the coefficient on FE*OFFFEXCH is negative and significant.

The remaining columns confirm that the negative relation between ERC and OFFEXCH survives controls for the three factors that explain variation in earnings persistence (column 3) as well as controls for the four liquidity measures that are related to arbitrage costs (columns 4 to 7). The coefficient on FE*OFFEXCH remains negative and significant, although the magnitude declines substantially. We note that the contemporaneous price response is a less reliable measure of underreaction to earnings news, relative to the delayed price response, because prior research 
has shown that ERC is determined by a number of factors, some of which are likely correlated with OFFEXCH. Such factors include leakage of earnings news prior to its public disclosure, earnings persistence, and risk. We therefore view these results as being suggestive, not conclusive, about the two main findings discussed above.

\subsection{Controls for other measures of arbitrage costs.}

In our main analysis, we control for intraday high-frequency measures of liquidity: ESPD and DEP, which are conceptually better than low-frequency measures. It is possible that lowfrequency measures of liquidity, which are more popular and cover more aspects of liquidity, better explain the relation between OFFEXCH and PEAD. We begin with the regression specification in column (6) of Panels A and B of Table 4 and include seven additional low-frequency liquidity measures that might reasonably capture arbitrage costs: ${ }^{21}$ The Amihud (2002) liquidity measure; level of institutional ownership; share price; intraday quoted spread; market capitalization; share turnover; and on-exchange share turnover. We include these measures one at a time as well as jointly. The results in Table A2 of the online Appendix suggest that while the inclusion of these variables increases the overall explanatory power (e.g. $\mathrm{R}^{2}$ increases from $52 \%$ to $60 \%$ when earnings news is defined as EARET), the magnitude and significance of the coefficients on SUR*OFFEXCH in Panels A and B-corresponding to earnings news measured as EARET and $\mathrm{FE}$, respectively—remain relatively unchanged. ${ }^{22}$

The measures of effective spread and depth considered in the base specification in Table 4 are based on pooling all trades during the pre-announcement window and giving each trade the

21 We do not use column (7) as our base specification because intraday return volatility is not as relevant a proxy for arbitrage costs, given that PEAD evolves over a long horizon. Moreover, the adjusted $\mathrm{R}^{2}$ in column (7) is not higher than that in column (6).

22 Untabulated results indicate that this finding persists when we replace all liquidity measures, high and low frequency, with their first two principal components, estimated both over the pooled sample as well as separately for each quarter (to avoid a look-ahead bias). 
same weight. It's likely that the relevant costs faced by arbitrageurs reflect spread and depth associated with just on-exchange trades, and the weight given to measures associated with different trades varies depending on their relevance to specific arbitrage trading strategies. To investigate this possibility, we begin with the base case and switch to depth/spread for just on-exchange trades, and consider four alternative weighting schemes: equal weight; value weight based on onexchange turnover; value weight based on off-exchange turnover; and value weight based on absolute value of return. The results reported in Panels A and B of Table A3 in the online Appendix indicate little change in the coefficients on SUR*OFFEXCH, relative to the base case. Overall, OFFEXCH remains a reasonable proxy for arbitrage costs as it explains variation in PEAD beyond that explained by a host of other candidates.

\subsection{Controls for intraday inefficiency.}

Our results suggest that intraday inefficiency and PEAD differ in their relation with OFFEXCH: whereas intraday inefficiency declines with the positive effect of OFFEXCH on signal-to-noise ratios, PEAD increases with the negative effect on liquidity. We investigate next whether the two relations are independent or mirror each other, by adding an interaction between OFFEXCH and intraday inefficiency to the base PEAD regressions from Table 4. We consider the same three intervals as in Table 3 when measuring variance ratios (VRATIO), but consider three different ways to estimate intraday inefficiency. We measure VRATIO over just the earnings announcement window as well as just over the pre-announcement window. We also consider the signed value of VRATIO, rather than the traditional approach of using absolute values, estimated over the announcement window. Whereas absolute values of VRATIO commingle under and overreaction, signed values allow separation of intraday underreaction from overreaction.

We find the magnitude and significance of the coefficient on SUR*OFFEXCH in Panels A and B of Table A4 of the online appendix to be similar to those reported in column (6) of Panels 
A and B of Table 4. Stated differently, the positive relation between OFFEXCH and PEAD appears to be independent of its negative relation with intraday inefficiency.

\subsection{Importance of retail internalization.}

Our final robustness analysis considers the importance of retail internalization, one of the four venues associated with OFFEXCH. Our motivation to do so arises from untabulated analyses we conducted that examines variation in different cuts of the sample based on observable attributes of trades that allow insights about the specific source/factor that generates a positive relation between OFFEXCH and PEAD. Examples of cuts we consider include ATS (i.e. alternative trading system) versus non-ATS venues; block versus non-block trades; trades executed at the midpoint, within, and outside quoted bid/ask prices; and trades executed at half-penny, sub-penny (fractions other than half), and round pennies. ATS venues comprise crossing networks and nondisplayed limit order books, whereas non-ATS venues comprise PING destinations and retail internalization. ${ }^{23}$ Block trades are more likely to be uninformed trades that are executed in crossing networks at the midpoint of bid/ask prices, relative to non-block trades. Retail internalization is more likely to appear as sub-penny trades, whereas on-exchange trades at quoted ask/bid prices are more likely to be round penny trades.

We replace the SUR*OFFEXCH interaction in the base PEAD specification with interactions between SUR and the different subsamples created in each cut. For example, we replace SUR*OFFEXCH with SUR*ATS and SUR*non-ATS. We are unable to find consistent patterns across the different specifications that allow us to narrow the subset of off-exchange trades that drive the overall positive relation with PEAD. For example, block trades exhibit significant coefficients, and even larger magnitudes than non-block trades when earnings news is measured

23 ATS trading volume, beginning in May 2014, is available on a weekly basis from the FINRA OTC Transparency Data website (https://otctransparency.finra.org/TradingDetailFile). 
by FE, and yet the interaction with midpoint trades is insignificant.

One coefficient estimate that is large and significant is the interaction with non-ATS, when earnings news is measured as EARET (it is insignificant for FE). This raises the potential that it is variation in retail-trading - one of the two venues included in non-ATS - that is mainly responsible for the observed relation between OFFEXCH and PEAD. The significant results we observe in Table 3 for the pilot project natural experiment suggest otherwise because retail trades are by design excluded from the restrictions imposed on the treatment group. Regardless, we consider three possible ways in which retail trades might create the observed positive relation. They are based on the assumption that retail trades represent noise trades that create the originating underreaction to earnings news. ${ }^{24}$

First, firms with high levels of retail trades might exhibit lower pre-announcement anticipatory response to upcoming earnings news, which then surfaces as higher postannouncement price responses. We replace returns over the next quarter in the base specification with returns during the pre-announcement period and report results in columns (1) and (4) of Table A5 in the online Appendix. The coefficient on SUR*OFFEXCH, which should be negative under this alternative explanation, is positive for both measures of earnings news (and significant for FE).

Second, firms with high levels of retail trades are also likely to be associated with high buy/sell imbalances during earnings announcement windows that are contrary to the news announced. Stated differently, the observed underreaction associated with OFFEXCH that remains after controlling for liquidity measures is due to just the originating mispricing by noise traders (which are all retail traders under this alternative explanation) not arbitrage activity that is not fully

24 We recognize that this assumption runs counter to the evidence in Boehmer et al. (2017), which suggests that retail trades - both on and off-exchanges - are on average informed and predict future returns. 
captured by the included liquidity measures. We use the Boehmer et al. (2017) methodology to identify retail trades (based on the fraction of total trades that are sub-penny trades) and the Lee and Ready (1991) methodology to separate buys and sells. This allows a measure of abnormal retail net purchases during the announcement window, relative to levels in the pre-announcement window. Our results reported in columns (2) and (5) of Table A5 indicate insignificant coefficients on this retail buy/sell imbalance variable and coefficients on SUR*OFFEXCH that are similar in magnitude and significance to the base case.

Finally, firms with high levels of retail trades are associated with a general level of mispricing that is not reflected specifically in buy/sell imbalance during the announcement window. We include an interaction between retail trading volume, based on the Boehmer et al. (2017) methodology, and earnings surprise. Again, the coefficient estimates on this interaction are insignificant, and the estimates on SUR*OFFEXCH are only slightly smaller in magnitude and significance to the base case.

\section{Concluding thoughts}

Off-exchange trading on dark venues, with no pre-trade transparency, has increased substantially over the past 30 years, raising concerns among regulators and exchanges about its impact on price discovery. Microstructure research suggests that OFFEXCH increases segmentation: patient, uninformed, liquidity trades that value price improvement move to dark venues, while informed trades that value immediacy of execution gravitate toward exchanges. This segmentation reduces liquidity because of the increased risk of adverse selection for liquidity providers. And yet the evidence suggests OFFEXCH reduces deviation of intraday price movements from random walks (intraday inefficiency). Consistent with the theory in Zhu (2014), this improvement in price discovery is likely due to the higher on-exchange signal-to-noise ratio 
generated by moving uninformed, liquidity trades to dark venues. We investigate whether this trade-off between reduced liquidity and improved signal-to-noise ratio creates a similar negative relation with an accounting price inefficiency: underreaction to earnings news.

Our investigation reveals a positive, not negative, relation between OFFEXCH and PEAD. This result holds for a comprehensive panel of US firms as well as for a natural experiment conducted by the SEC on a small sample of low capitalization firms. This finding is consistent with the liquidity effect of OFFEXCH dominating the signal-to-noise ratio effect for this inefficiency. The liquidity effect is likely more important for PEAD because of the role played by arbitrageurs: they correct underreaction to earnings news, but only up to the limit of arbitrage costs which are likely increased when liquidity declines.

The positive relation between OFFEXCH and underreaction remains significant, both statistically and economically, despite the inclusion of controls for a host of proxies for liquidity faced by arbitrageurs. This incremental ability of OFFEXCH to explain mispricing arises from two possible source. First, traditional liquidity proxies measure true costs faced by arbitrageurs with error. For example, the average effective spreads we use in our analyses may not reflect the effective spread faced by arbitrageurs. Second, observed transactions costs represent only the tip of the iceberg (Lee and So 2015), as arbitrageurs face a variety of other costs.

Overall, we document that OFFEXCH represents an important source of underreaction to earnings news. Our results support the view that observed underreaction reflects the net effect of noise traders underreacting to earnings news and arbitrageurs trading in the direction of earnings news, up to the limit of arbitrage costs. Apparently, the reduced liquidity created by OFFEXCH increases these arbitrage limits. Our finding that OFFEXCH continues to explain a substantial 
fraction of variation in PEAD suggests that it be used as a proxy for arbitrage costs by researchers studying the role of arbitrage in mispricing. 


\section{References}

Admati, A. and Pfleiderer, P., 1988. A theory of intraday patterns: Volume and price variability. The Review of Financial Studies, 1(1), 3-40.

Amihud, Y., 2002. Illiquidity and stock returns: cross-section and time-series effects. Journal of financial markets, 5(1), 31-56.

Ball, R. and Brown, P., 1968. An empirical evaluation of accounting income numbers. Journal of accounting research, 159-178.

Battalio, R., 1997. Third Market Broker-Dealers: Cost Competitors or Cream Skimmers? The Journal of Finance, 52(1), 341-352.

Battalio, R., Corwin, S. and Jennings, R., 2016. Can Brokers Have It All? On the Relation between Make-Take Fees and Limit Order Execution Quality. The Journal of Finance, $71(5), 2193-2238$

Battalio, R., Greene, J. and Jennings, R., 1998. Order Flow Distribution, Bid-Ask Spreads, and Liquidity Costs: Merrill Lynch's Decision to Cease Routinely Routing Orders to Regional Stock Exchanges. Journal of Financial Intermediation, 7(4), 338-358.

Bernard, V. and Thomas, J., 1989. Post-earnings-announcement drift: delayed price response or risk premium? Journal of Accounting research, 1-36.

Bernard, V. and Thomas, J., 1990. Evidence that stock prices do not fully reflect the implications of current earnings for future earnings. Journal of Accounting and Economics, 13(4), 305-340.

Bhushan, R. 1994. An informational efficiency perspective on the post-earnings announcement drift. Journal of Accounting and Economics, 18(1), 45-65.

Boehmer, E., Jones, C., and Zhang, X. 2017. Tracking Retail Investor Activity. Available at SSRN: https://ssrn.com/abstract=2822105

Buti, S., Rindi, B. and Werner, I., 2017. Dark pool trading strategies, market quality and welfare. Journal of Financial Economics, 124(2), 244-265.

Cao, S. and Narayanamoorthy, G., 2012. Earnings volatility, post-earnings announcement drift, and trading frictions. Journal of Accounting Research, 50(1), 41-74.

CFA Institute, 2012. Dark pools, internalization, and equity market quality. http://www.cfapubs.org/doi/abs/10.2469/ccb.v2012.n5.1

Chakravarty, S. and Sarkar, A., 2002. A model of broker's trading, with applications to order flow internalization. Review of Financial Economics, 11(1), 19-36.

Cheong, F.S. and Thomas, J., 2017. Management of reported and forecast EPS, investor responses, and research implications. Management Science, Articles in Advance, pp. 125. 
Chordia, T., Goyal, A., Sadka, G., Sadka, R. and Shivakumar, L. 2009. Liquidity and the postearnings-announcement drift. Financial Analysts Journal, 65(4), 18-32.

Chordia, T. and Subrahmanyam, A., 1995. Market making, the tick size, and payment-for-order flow: theory and evidence. Journal of Business, 543-575.

Chordia, T., Subrahmanyam, A. and Tong, Q., 2014. Have capital market anomalies attenuated in the recent era of high liquidity and trading activity? Journal of Accounting and Economics, 58(1), 41-58.

Chung, K.H., Chuwonganant, C. and McCormick, D.T., 2004. Order preferencing and market quality on NASDAQ before and after decimalization. Journal of Financial Economics, 71(3), 581-612.

Cohen, D.A., Dey, A., Lys, T.Z. and Sunder, S.V., 2007. Earnings announcement premia and the limits to arbitrage. Journal of Accounting and Economics, 43(2), pp.153-180.

Comerton-Forde, C. and Putniņš, T.J., 2015. Dark trading and price discovery. Journal of Financial Economics, 118(1), 70-92.

Comerton-Forde, C., Gregoire, V. and Zhong, Z., 2018. Inverted Fee Structures, Tick Size, and Market Quality. Available at SSRN: https://ssrn.com/abstract=2939012

Dutta, P.K. and Madhavan, A., 1997. Competition and collusion in dealer markets. The Journal of Finance, 52(1), 245-276.

Easley, D., Kiefer, N.M. and O'Hara, M., 1996. Cream-skimming or profit-sharing? The curious role of purchased order flow. The Journal of Finance, 51(3), 811-833.

Farley, R., Kelley, E. and Puckett, A., 2018. Dark Trading Volume and Market Quality: A Natural Experiment. Available at SSRN: https://ssrn.com/abstract=3088715

Foley, S. and Putniņš, T., 2016. Should we be afraid of the dark? Dark trading and market quality. Journal of Financial Economics, 122(3), 456-481.

Foster, G., Olsen, C. and Shevlin, T., 1984. Earnings releases, anomalies, and the behavior of security returns. Accounting Review, 59(4), 574-603.

Gkougkousi, X. and Landsman, W., 2018. Dark Trading Volume at Earnings Announcements. Available at SSRN: https://ssrn.com/abstract $=3007697$

Gow, I., Ormazabal, G., and Taylor, D. 2010. Correcting for Cross Sectional and Time Series Dependence in Accounting Research. The Accounting Review, 85 (2), 483-512.I

Hansen, P., Li, Y., Lunde, A., and Patton, A., 2017. Mind the Gap: An Early Empirical Analysis of SEC's "Tick Size Pilot Program". Working Paper.

Hasbrouck, J., 1995. One security, many markets: Determining the contributions to price discovery. The journal of Finance, 50(4), 1175-1199.

Haslag, P. and Ringgenberg, M., 2016. The Causal Impact of Market Fragmentation on Liquidity. Available at SSRN: https://ssrn.com/abstract=2591715 
Hatheway, F., Kwan, A. and Zheng, H., 2017. An Empirical Analysis of Market Segmentation on US Equity Markets. Journal of Financial and Quantitative Analysis, 52(6), pp.23992427.

Hendershott, T. and Mendelson, H., 2000. Crossing networks and dealer markets: Competition and performance. The Journal of Finance, 55(5), 2071-2115.

Heston, S., Korajczyk, R. and Sadka, R., 2010. Intraday patterns in the cross-section of stock returns. The Journal of Finance, 65(4), 1369-1407.

Holden, C., Jacobsen, S. and Subrahmanyam, A. 2014. The empirical analysis of liquidity. Foundations and Trends ${ }^{\circledR}$ in Finance, 8(4), pp.263-365.

Jiang, C., McInish, T. and Upson, J., 2012. Market Fragmentation and Information Quality: The Role of TRF Trades. Available at SSRN: https://ssrn.com/abstract=1960115

Johnson, W. and Schwartz, W., 2000. Evidence that capital markets learn from academic research: Earnings surprises and the persistence of post-announcement drift. Available at SSRN 255603.

Joy, O., Litzenberger, R. and McEnally, R., 1977. The adjustment of stock prces to announcements of unanticipated changes in quarterly earnings. Journal of Accounting Research, 15(2), 207-225.

Ke, B. and Ramalingegowda, S., 2005. Do institutional investors exploit the post-earnings announcement drift? Journal of Accounting and Economics, 39(1), 25-53.

Kluger, B. and Wyatt, S., 2002. Preferencing, internalization of order flow, and tacit collusion: evidence from experiments. Journal of Financial and quantitative Analysis, 37(3), 449469.

Kwan, A., Masulis, R. and McInish, T., 2015. Trading rules, competition for order flow and market fragmentation. Journal of Financial Economics, 115(2), pp.330-348.

Kyle, A., 1989. Informed speculation with imperfect competition. The Review of Economic Studies, 56(3), 317-355.

Lee, C. and Ready, M.J., 1991. Inferring trade direction from intraday data. The Journal of Finance, 46(2), 733-746.

Lee, C. and So, E. 2015. Alphanomics: The Informational Underpinnings of Market Efficiency. Foundations and Trends in Accounting, 9(2-3), 59-258.

Lo, A. and MacKinlay, A., 1988. Stock market prices do not follow random walks: Evidence from a simple specification test. The review of financial studies, 1(1), 41-66.

Mendenhall, R., 2004. Arbitrage Risk and Post-Earnings-Announcement Drift. The Journal of Business, 77(4), 875-894.

Menkveld, A.J., Yueshen, B.Z. and Zhu, H., 2017. Shades of darkness: A pecking order of trading venues. Journal of Financial Economics, 124(3), 503-534. 
Milian, J., 2015. Unsophisticated Arbitrageurs and Market Efficiency: Overreacting to a History of Underreaction? Journal of Accounting Research, 53(1), 175-220.

Narayanamoorthy, G., 2006. Conservatism and Cross-Sectional Variation in the Post-Earnings Announcement Drift. Journal of Accounting Research, 44(4), 763-789.

Ng, J., Rusticus, T. and Verdi, R., 2008. Implications of transaction costs for the post-earnings announcement drift. Journal of Accounting Research, 46(3), 661-696.

Nimalendran, M. and Ray, S., 2014. Informational linkages between dark and lit trading venues. Journal of Financial Markets, 17, 230-261.

O'Hara, M. and Ye, M. 2011. Is market fragmentation harming market quality? Journal of Financial Economics, 100(3), 459-474.

Rangan, S. and Sloan, R. 1998. Implications of the integral approach to quarterly reporting for the post-earnings-announcement drift. The Accounting Review, 353-371.

Reed, A., Samadi, M. and Sokobin, J. 2018. Shorting in Broad Daylight: Short Sales and Venue Choice. Available at SSRN: https://ssrn.com/abstract=3210821

Richardson, S., Tuna, İ. and Wysocki, P. 2010. Accounting anomalies and fundamental analysis: A review of recent research advances. Journal of Accounting and Economics, 50(2), 410 454.

Rindi, B. and Werner, I., 2017. U.S. Tick Size Pilot. Available at SSRN: https://ssrn.com/abstract $=3041644$

Rosenblatt Securities. 2018. Assessment of the Plan to Implement a Tick Size Pilot Program. http://www.finra.org/industry/assessment-plan-implement-tick-size-pilot-program

Securities and Exchange Commission. 2010. Concept release on equity market structure. https://www.sec.gov/rules/concept/2010/34-61358.pdf

Securities and Exchange Commission. 2015. Plan to implement a tick size pilot program. http:/www.sec.gov/rules/sro/nms/2015/34-74892-exa.pdf

Tetlock, P., 2010. Does public financial news resolve asymmetric information? The Review of Financial Studies, 23(9), 3520-3557.

Weaver, D., 2011. Internalization and market quality in a fragmented market structure. http://ssrn.com/abstract=1846470.

Zhu, H. 2014. Do dark pools harm price discovery? The Review of Financial Studies, 27 (3): 747-789. 


\section{Appendix: Variable definitions}

The current quarter is labeled quarter $\mathrm{q}$, and the prior (next) quarter is $\mathrm{q}-1(\mathrm{q}+1)$. The earnings announcement window includes day 0 and day +1 . The pre-announcement window, for which we require a minimum of 30 trading days, begins on day +2 of quarter q-1's earnings announcement and ends on day -1 of quarter q's earnings announcement. The post-announcement window begins on day +2 of quarter q's announcement and ends on day +1 after quarter q +1 's announcement.

\begin{tabular}{|c|c|}
\hline Variable & Definition \\
\hline \multicolumn{2}{|c|}{ Dependent variables } \\
\hline SARET $_{\mathrm{q}+1}$ & Size-adjusted returns over the post-announcement window. \\
\hline VRATIO $_{\mathrm{k} / 1}$ & $\begin{array}{l}\text { Average daily variance ratio (Lo and MacKinlay, } 1988) \text { over the pre- } \\
\text { announcement window. Daily variance ratio is defined as }\left|\frac{\sigma_{k l}^{2}}{k \sigma_{l}^{2}}-1\right| \text {, where } \sigma_{l}^{2} \text { and } \\
\sigma_{k l}^{2} \text { are the variances of } l \text {-minute and } k l \text {-minute mid-quote returns for a given } \\
\text { stock-day. We considers three combinations, (5-minutes, } 1 \text {-minute), (15-minutes, } \\
5 \text {-minutes), and (30-minutes, } 15 \text {-minutes), in the analysis. }\end{array}$ \\
\hline \multicolumn{2}{|c|}{ Main independent variables } \\
\hline OFFEXCH & $\begin{array}{l}\text { Off-exchange trading ratio over the pre-announcement window is defined as } \\
\text { average daily ratio of shares traded off stock exchanges to total number of shares } \\
\text { traded during regular hours (09:30 to 16:00) from the daily TAQ (DTAQ) } \\
\text { database. Off-exchange trades are indicated by exchange code = 'D', indicating it } \\
\text { was recorded on a trade reporting facility or TRF. }\end{array}$ \\
\hline EARET & Size-adjusted returns over the earnings announcement window. \\
\hline FE & $\begin{array}{l}\text { Analyst forecast error is IBES actual EPS minus IBES latest consensus mean } \\
\text { forecast, scaled by share price at quarter q's fiscal quarter end. }\end{array}$ \\
\hline \multicolumn{2}{|c|}{ Control variables explaining cross-sectional variation in drift } \\
\hline EVOL & $\begin{array}{l}\text { Natural logarithm of earnings volatility, which is defined as the standard deviation } \\
\text { of quarterly ROA (net income/average total assets) over the past } 8 \text { quarters. }\end{array}$ \\
\hline FQ4 & Indicator variable $=1$ if quarter $\mathrm{q}$ is a fiscal fourth quarter, $=0$ otherwise. \\
\hline LOSS & Indicator variable $=1$ if GAAP EPS of quarter $\mathrm{q}$ is negative, $=0$ otherwise. \\
\hline DEP & $\begin{array}{l}\text { Natural logarithm of average daily market depth at NBBO over the pre- } \\
\text { announcement window. Daily depth is defined as volume-weighted average dollar } \\
\text { depth at NBBO computed over all trades, including both on-exchange and off- } \\
\text { exchange trades, during regular trading hours in that day (see Holden et al. } 2014 \\
\text { for details). }\end{array}$ \\
\hline ESPD & $\begin{array}{l}\text { Average daily percentage effective spread over the pre-announcement window. } \\
\text { Daily percentage effective spread is volume-weighted average percentage effective } \\
\text { spread computed over all trades, including both on-exchange and off-exchange } \\
\text { trades, during regular trading hours in that day. The percentage effective spread is } \\
\text { twice the signed ('+' for buyer initiated and '-' for seller initiated) difference } \\
\text { between log price of the trade and log midpoint between NBBO one nanosecond } \\
\text { before the trade (see Holden et al. } 2014 \text { for details). For off-exchange trades, we } \\
\text { adjust reported trade time as described in the variable definition for MIDPOINT. } \\
\text { We use the Lee and Ready (1991) algorithm to determine whether a trade is buyer- } \\
\text { or seller- initiated. }\end{array}$ \\
\hline IDVOL & $\begin{array}{l}\text { Natural logarithm of idiosyncratic return volatility measured over the past year } \\
\text { ending in quarter q. We require a minimum of } 120 \text { trading days. }\end{array}$ \\
\hline
\end{tabular}




\begin{tabular}{|c|c|}
\hline IMPACT & $\begin{array}{l}\text { Average daily percentage price impact over the pre-announcement window. Daily } \\
\text { percentage price impact is volume-weighted average percentage price impact } \\
\text { computed over all trades during regular trading hours in that day. The percentage } \\
\text { price impact of a trade is twice the signed ('+' for buyer initiated and '-' for seller } \\
\text { initiated) difference between log midpoint between NBBO five minutes after the } \\
\text { trade and the log midpoint between NBBO one nanosecond before the trade (see } \\
\text { Holden et al. } 2014 \text { for details). We use the Lee and Ready (1991) algorithm to } \\
\text { determine whether a trade is buyer- or seller- initiated. }\end{array}$ \\
\hline RSPD & $\begin{array}{l}\text { Average daily percentage realized spread over the pre-announcement window. } \\
\text { Daily percentage realized spread is volume-weighted average percentage realized } \\
\text { spread computed over all trades during regular trading hours in that day. The } \\
\text { percentage realized spread of a trade is twice the signed ('+' for buyer initiated and } \\
\text { '-' for seller initiated) difference between log trade price and log midpoint between } \\
\text { NBBO five minutes after the trade (see Holden et al. } 2014 \text { for details). We use the } \\
\text { Lee and Ready (1991) algorithm to determine whether a trade is buyer- or seller- } \\
\text { initiated. }\end{array}$ \\
\hline VAR & $\begin{array}{l}\text { Natural logarithm of average daily intraday mid-quote return variance over the } \\
\text { pre-announcement window. Intraday mid-quote return is computed at 1-minute } \\
\text { frequency. }\end{array}$ \\
\hline \multicolumn{2}{|c|}{ Control variables explaining cross-sectional variation in returns } \\
\hline BETA & $\begin{array}{l}\text { Equity beta over the past year ending in quarter q, with a minimum requirement of } \\
120 \text { trading days. }\end{array}$ \\
\hline BTM & $\begin{array}{l}\text { Book-to-market ratio is defined as book value of common shareholders' equity at } \\
\text { the beginning of quarter q divided by the market value at the end of quarter q. }\end{array}$ \\
\hline MOM11 & $\begin{array}{l}\text { Compounded returns over the } 11 \text {-month window ending in the } 2 \text { nd month of } \\
\text { current quarter. We require a minimum of } 120 \text { trading days. }\end{array}$ \\
\hline SIZE & Natural logarithm of market value at the end of quarter q. \\
\hline
\end{tabular}




\section{Figure 1. Time-series of average levels of off exchange trading}

This figure plots the quarter-by-quarter sample means for off-exchange trading ratio (OFFEXCH). The sample includes 74,190 firm-quarters from the first quarter of 2009 to the second quarter of 2017.

OFFEXCH for a firm-quarter equals the average of daily percentages across trading days in that quarter. All variables are measured over a pre-announcement window. See Appendix for details of variables.

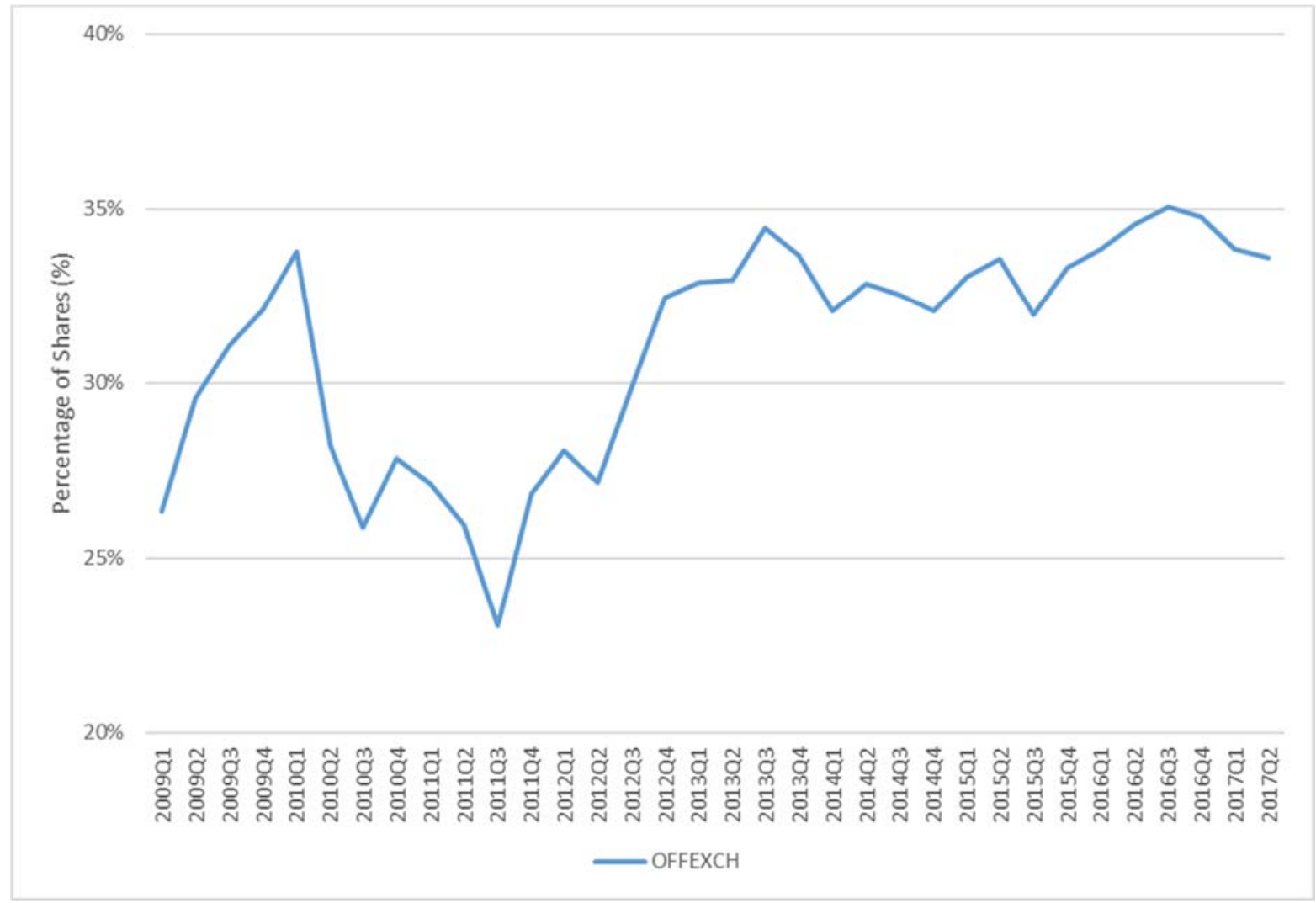




\section{Figure 2: Impact of SEC Tick Size Pilot Program on off-exchange trading}

This figure plots the daily portfolio mean of the percentage of shares traded off stock exchanges for our treatment group and control group in the SEC Tick Size Pilot sample. Daily off-exchange trading ratios are plotted for the two-year window around the staggered implementation of the pilot program during October 2016. The Tick Size Pilot program refers to our treatment and control groups as test group three (TEST G3) and test group one (TEST G1), respectively. Daily list of stocks included in the pilot program is available at http://www.finra.org/industry/tick-size-pilotprogram.

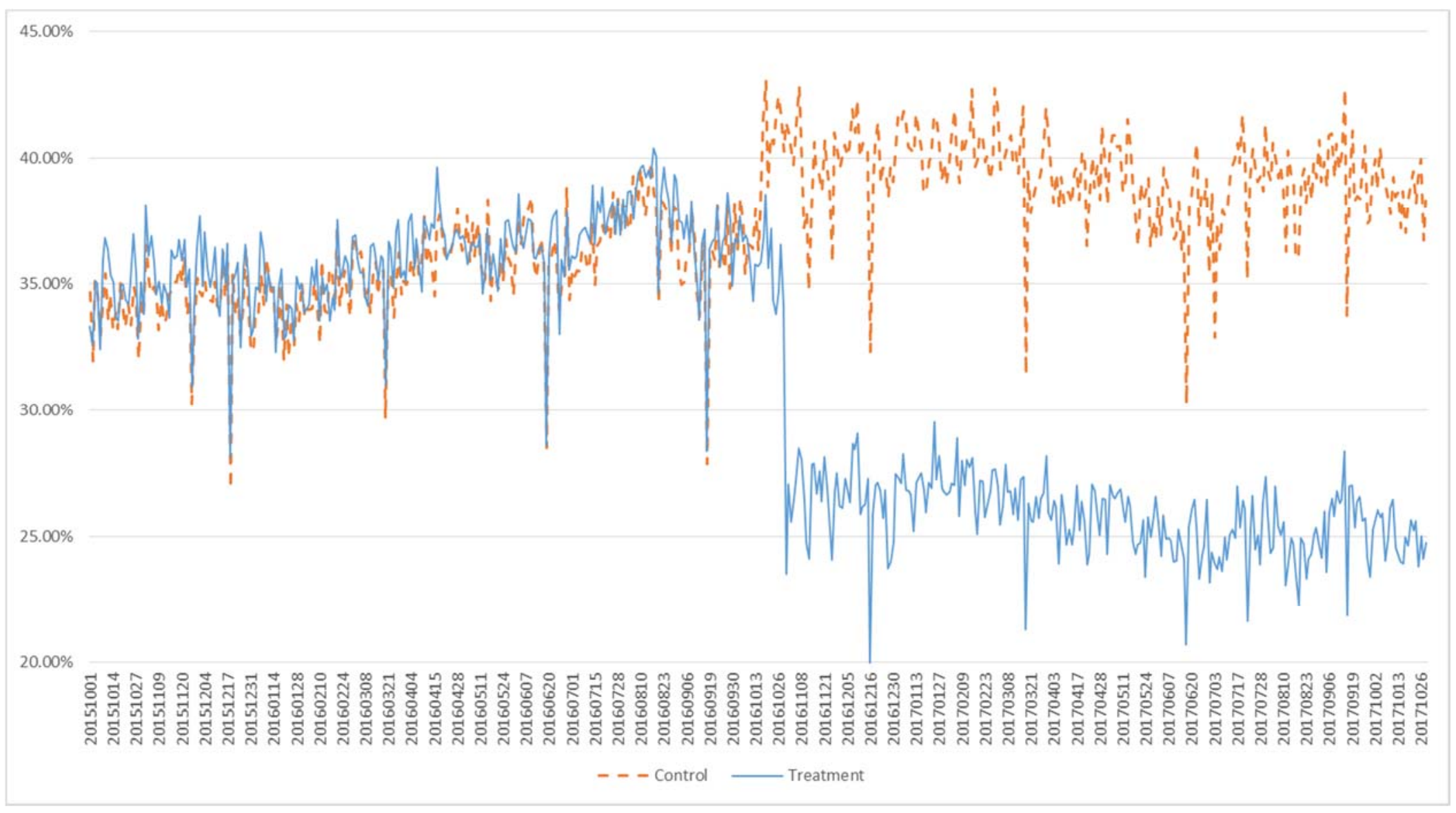




\section{Figure 3: Relation between off-exchange trading and post-earnings-announcement-drift}

We plot mean size-adjusted returns over the next quarter $\left(\mathrm{SARET}_{\mathrm{q}+1}\right)$ for the lowest $(\mathrm{Q} 1)$ and highest (Q5) quintile of earnings surprise, across quintiles of off-exchange trading ratio (OFFEXCH). Earnings surprise is measured as earnings announcement returns (EARET) in Panel A and analyst forecast error (FE) in Panel B. OFFEXCH for a firm-quarter is the average daily percentage of shares traded off stock exchanges to total number of traded shares, measured over a pre-announcement window. Portfolio "Q5 Q1 of EARET" and "Q5 - Q1 of FE" represents returns to a hedge portfolio constructed by investing long/short in Q5/Q1 for the corresponding measures of earnings surprise. The sample is ranked independently into quintile portfolios of earnings surprise and off-exchange ratio for each calendar quarter. We report means of portfolio returns for each calendar quarter in our sample. The sample includes 74,190 firm-quarters from 2009Q1 to 2017Q2. See Appendix for details of variables.

Panel A. Earnings surprise is defined as earnings announcement return (EARET)

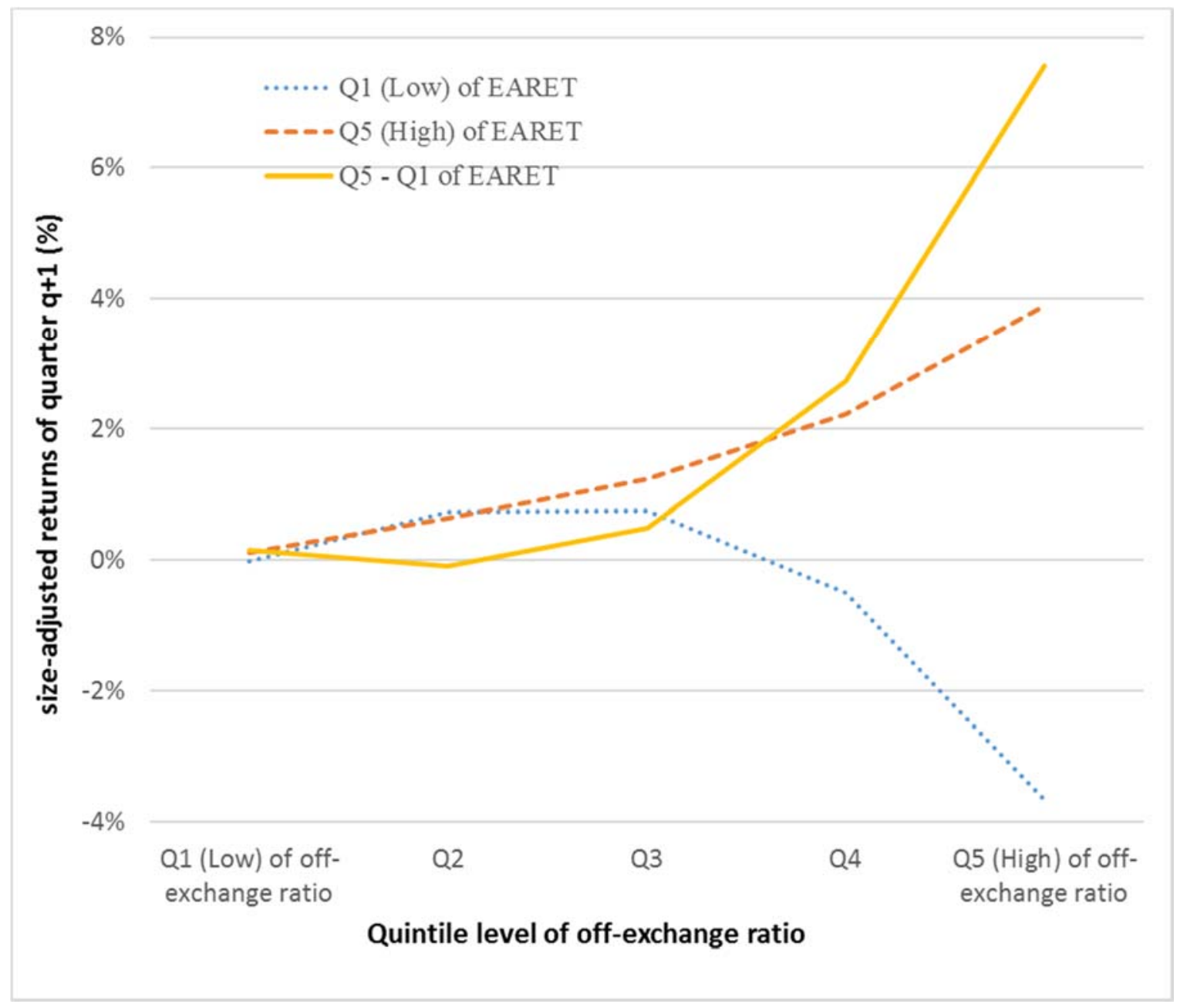


Panel B. Earnings surprise is defined as analyst forecast error (FE)

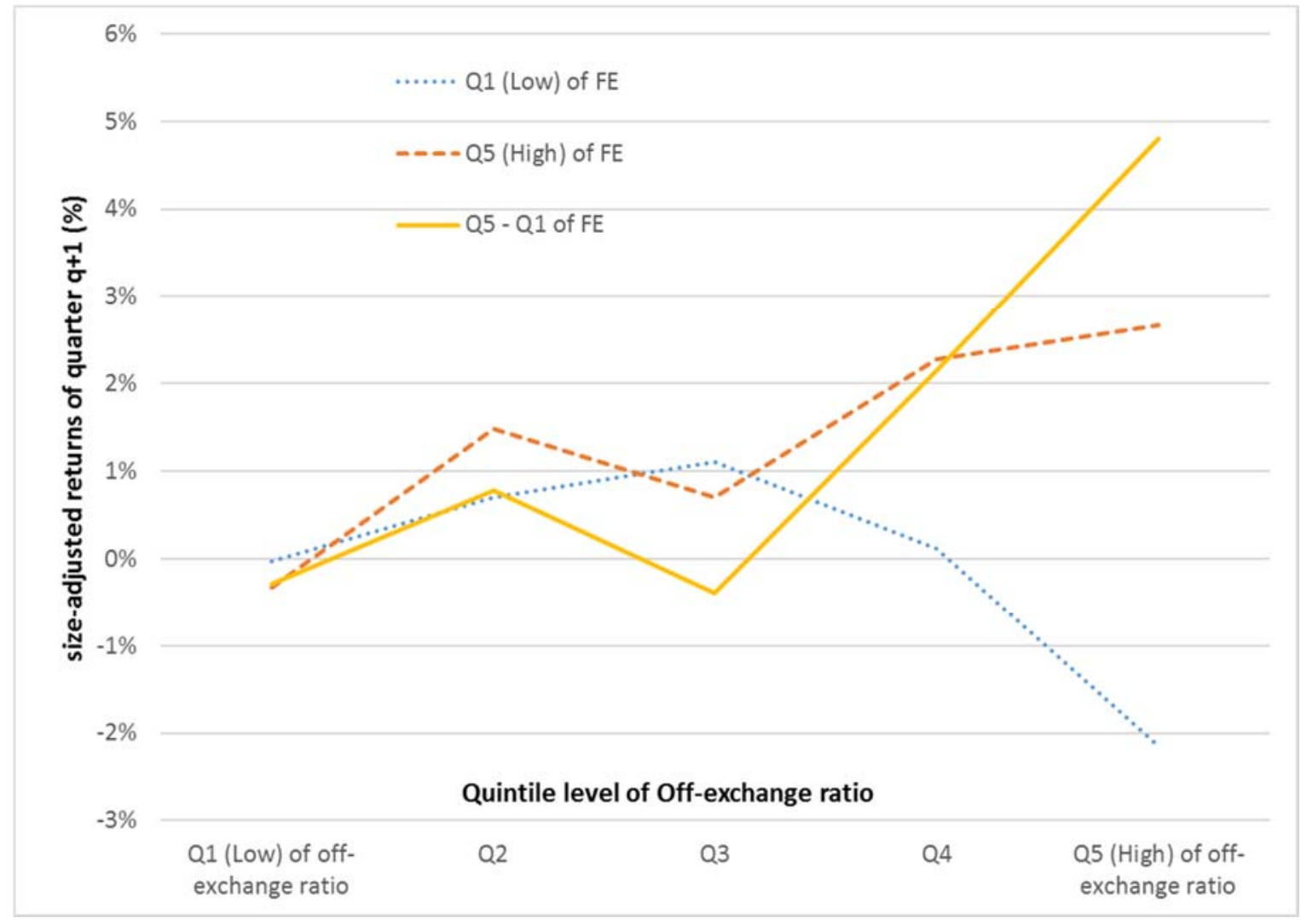




\section{Figure 4: Variation over time in the relation between off-exchange trading and post- earnings-announcement-drift (PEAD)}

The dashed (solid) line in these figures is the coefficient estimate $\beta_{0}$ on SUR ( $\beta_{1}$ on SUR $*$ OFFEXCH) from the first (second) quarterly, cross-sectional regression below:

SARET $_{\mathrm{q}+1}=\alpha+\beta_{0} * \mathrm{SUR}+$ Controls $+\varepsilon$.

SARET $_{\mathrm{q}+1}=\alpha+\beta_{0} *$ SUR $+\beta_{1} *$ SUR $*$ OFFEXCH $+\beta_{2} *$ OFFEXCH + Controls $+\varepsilon$.

SARET $_{\mathrm{q}+1}$ is the size-adjusted return over the next quarter, SUR is earnings surprise defined as sizeadjusted returns at current quarterly earnings announcement (EARET) in Panel A and analyst forecast error (FE) in Panel B. OFFEXCH is the average daily percentage of shares traded off stock exchanges measured over a pre-announcement window. Controls variables are BETA, SIZE, BTM, and MOM11. All independent variables are ranked into deciles by calendar quarter and assigned values between -0.5 (lowest decile) and 0.5 (highest decile).

The coefficient $\beta_{0}$ in the first regression indicates the hedge portfolio return earned over the next quarter from investing long (short) in the highest (lowest) EARET or FE decile, unconditional on the level of OFFEXCH.

The coefficient $\beta_{0}$ in the second regression (not reported below) indicates the hedge portfolio returns earned over the next quarter from investing long (short) in the highest (lowest) EARET or FE decile, for the median level of OFFEXCH. The coefficient $\beta_{1}$ in the second regression indicates the change in that relation as OFFEXCH increases from the lowest to the highest decile.

The sample includes 74,190 firm-quarters from 2009Q1 to 2017Q2. See Appendix for details of variables.

Panel A. Earnings news is defined as earnings announcement return (EARET)

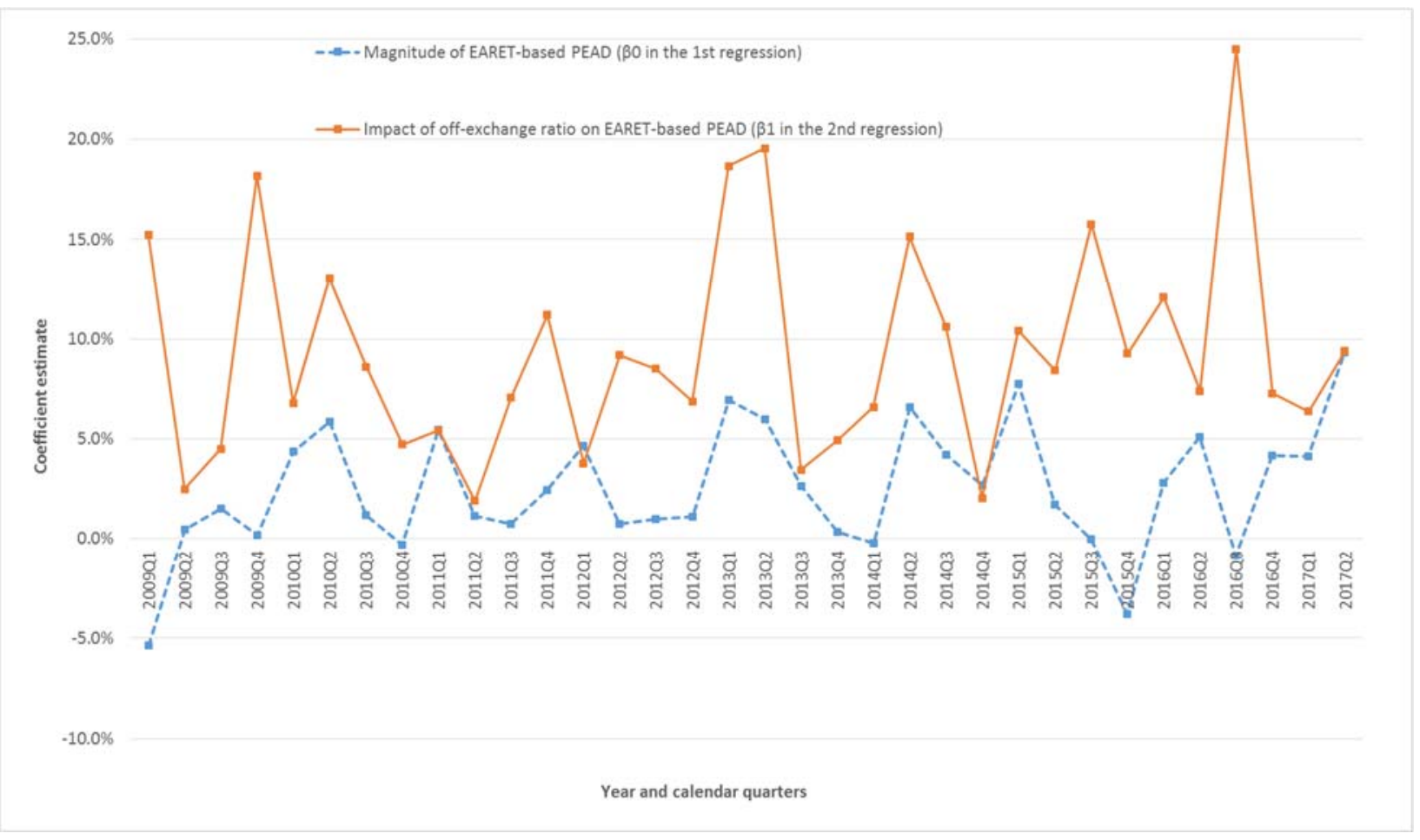


Panel B. Earnings news is defined as analyst forecast error (FE)

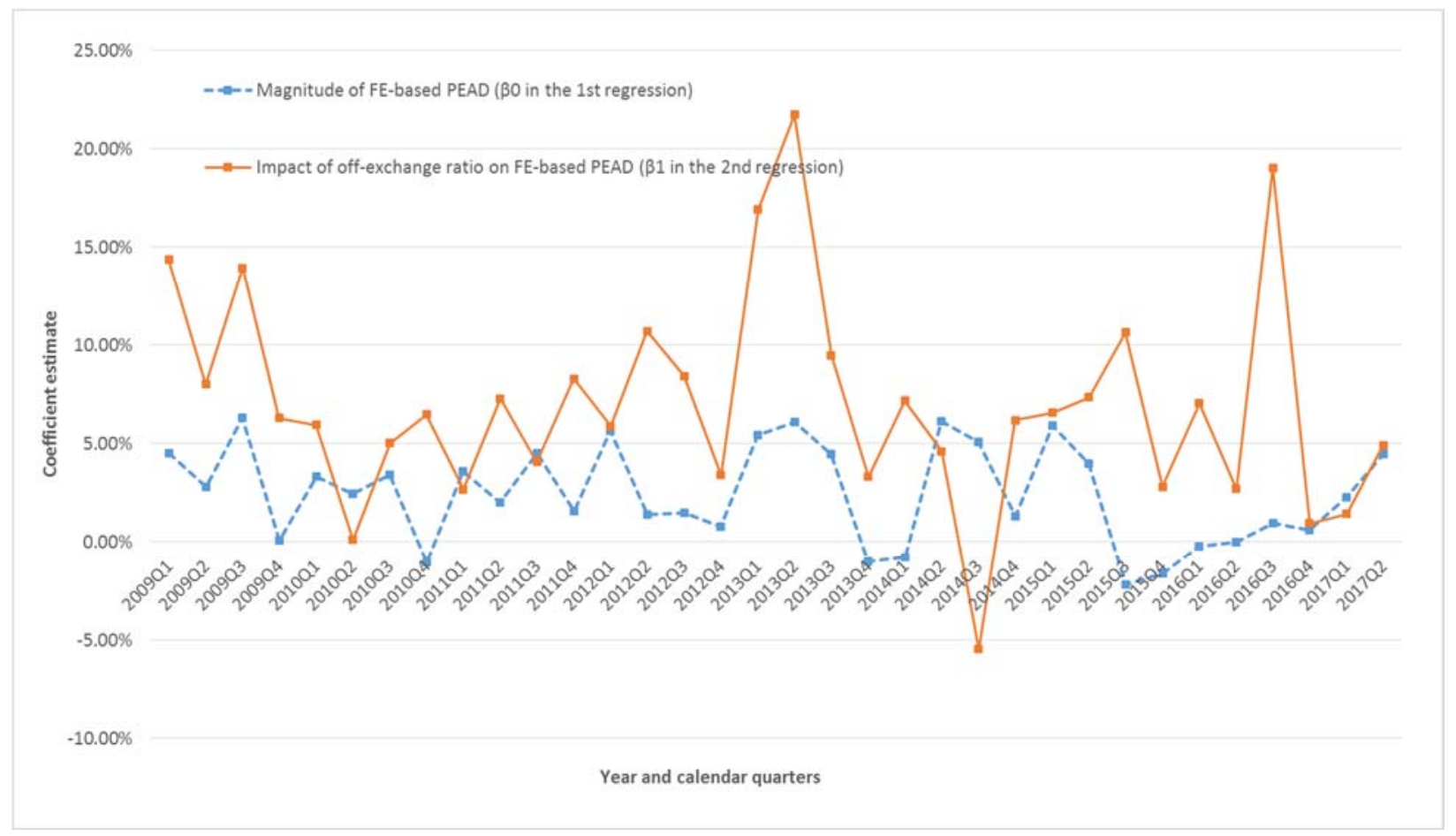


Table 1: Sample selection

\section{Panel A: Data collection for the main sample (panel) \\ Compustat/CRSP firm-quarters from 2009Q1 to 2017Q2 satisfying the \\ following requirements: \\ 1. earnings announcement date is no more than 92 calendar days after fiscal quarter end; and \\ 2. earnings announcement date is at least 30 trading days after previous quarterly earnings announcement.}

Firm-quarters remaining 142,943

Exclude financial firms (SIC code 6000-6999) 99,543

Require non-missing earnings news (two-day earnings announcement 82,524 returns and forecast error)

Require

74,250

1. share price at the end of the quarter to be at least $\$ 1$;

2. non-missing values for control variables that explain variation in returns (BETA, SIZE, BTM, and MOM11);

3. non-missing values for idiosyncratic return volatility and intraday mid-quote return variance; and

4. non-missing value for earnings volatility.

Require non-missing values for OFFEXCH calculated using Daily TAQ 74,190 data.

Final sample from 2009Q1 to 2017Q2

74,190

\section{Panel B: Data selection for the tick size pilot sample}

Firms/Firm-quarters remaining

Control

(SEC Test G1)

CRSP firms included in Tick Size Pilot Program test groups one and three as of October 2016, with daily quote and trade data before being delisted or rolled back into the tick size pilot control group (if so by 10/31/2017).

Exclude firms that have more than $50 \%$ of trading days with less than 20 trades per day in the one-year window before and the one-year window after the implementation of pilot program, following Rindi and Werner (2017). Require

1. Each trading day to have at least 20 trades
392

Treatment (SEC Test G3) 391 
2. A minimum of 30 trading days in both the oneyear window before and the one-year window after the implementation of pilot program

Firms available for liquidity analyses (daily-frequency)

Firm-quarters from 2015Q3 to 2017Q2 from sample above that satisfies the following requirements:

1. earnings announcement date is no more than 92 calendar days after fiscal quarter end; and

2. earnings announcement date is at least 30 trading days after previous quarterly earnings announcement.

Require

1. non-missing two-day earnings announcement returns;

2. non-missing values for control variables that explain variation in returns (BETA, SIZE, BTM, and MOM11); and

3. each quarter post pilot program implementation has a corresponding quarter ending in the same calendar quarter before pilot program implementation.

Firm-quarters available for PEAD analyses (quarterly frequency) 


\section{Table 2: Descriptive statistics for our main sample (panel)}

This table reports descriptive statistics for key variables in our analysis. Panel A reports distributional statistics, and Panel B reports the Spearman (below the diagonal) and Pearson (above the diagonal) correlations among these variables. The sample includes 74,190 firm-quarters from 2009Q1 to 2017Q2. See Appendix for details of variables.

${ }^{*},{ }^{* *},{ }^{* * *}$ denote two-tailed $\mathrm{p}$-values $<0.10,<0.05,<0.01$, respectively.

Panel A: Variable distributions

\begin{tabular}{|l|c|c|c|c|c|}
\hline & Mean & Median & $\begin{array}{c}\text { Standard } \\
\text { deviation }\end{array}$ & First Quartile & Third Quartile \\
\hline VRATIO $_{5 / 1}$ & 0.21 & 0.21 & 0.04 & 0.19 & 0.23 \\
\hline VRATIO $_{15 / 5}$ & 0.26 & 0.26 & 0.04 & 0.23 & 0.28 \\
\hline VRATIO $_{30 / 15}$ & 0.26 & 0.27 & 0.04 & 0.25 & 0.29 \\
\hline SARET $^{+}+1$ & $0.46 \%$ & $-0.56 \%$ & $22.35 \%$ & $-10.27 \%$ & $9.37 \%$ \\
\hline FE & $0.00 \%$ & $0.05 \%$ & $1.51 \%$ & $-0.12 \%$ & $0.27 \%$ \\
\hline EARET & $0.01 \%$ & $-0.11 \%$ & $8.21 \%$ & $-4.25 \%$ & $4.22 \%$ \\
\hline OFFEXCH & $31.03 \%$ & $29.52 \%$ & $9.06 \%$ & $25.06 \%$ & $35.34 \%$ \\
\hline LOSS & 0.31 & 0.00 & 0.46 & 0.00 & 1.00 \\
\hline FQ4 & 0.24 & 0.00 & 0.43 & 0.00 & 0.00 \\
\hline EVOL & -4.36 & -4.48 & 1.18 & -5.22 & -3.59 \\
\hline ESPD & 0.00 & 0.00 & 0.01 & 0.00 & 0.00 \\
\hline DEP & 9.43 & 9.34 & 0.99 & 8.71 & 10.03 \\
\hline IDVOL & -3.82 & -3.83 & 0.54 & -4.20 & -3.45 \\
\hline VAR & -13.10 & -13.20 & 1.36 & -14.03 & -12.33 \\
\hline BETA & 1.19 & 1.15 & 0.48 & 0.86 & 1.47 \\
\hline SIZE & 13.88 & 13.81 & 1.83 & 12.56 & 15.08 \\
\hline BTM & 0.50 & 0.41 & 0.46 & 0.22 & 0.68 \\
\hline MOM11 & $15.67 \%$ & $9.11 \%$ & $55.89 \%$ & $-15.00 \%$ & $34.43 \%$ \\
\hline & & & & & \\
\hline
\end{tabular}




\section{Table 2 (continued.)}

Panel B: Correlation coefficients (Spearman below the diagonal, and Pearson above the diagonal)

\begin{tabular}{|c|c|c|c|c|c|c|c|c|c|c|c|c|c|c|c|c|}
\hline & 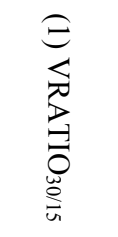 & 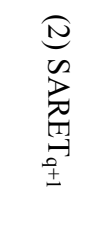 & $\begin{array}{l}\text { () } \\
\text { T] } \\
\vec{T}\end{array}$ & 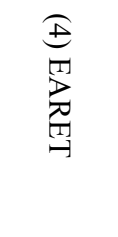 & 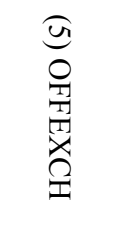 & $\begin{array}{l}0 \\
5 \\
0 \\
\infty \\
\infty\end{array}$ & $\begin{array}{l}\text { త } \\
\text { I } \\
0 \\
\perp\end{array}$ & 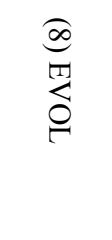 & 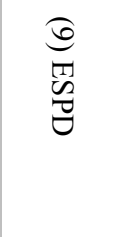 & 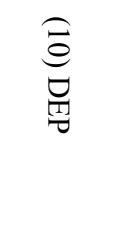 & $\begin{array}{l}\underset{\Xi}{\Xi} \\
\underset{ٍ}{ٍ} \\
ٍ\end{array}$ & 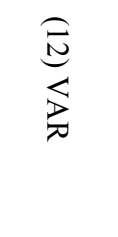 & 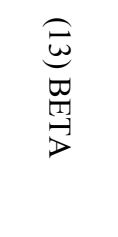 & 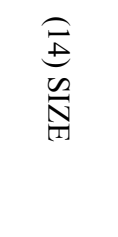 & $\begin{array}{l}\underset{\vec{G}}{\tilde{\sigma}} \\
\underset{3}{3}\end{array}$ & 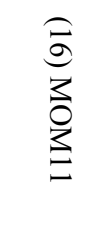 \\
\hline (1) & & 0.00 & & 0.00 & & $-0.08^{* * *}$ & & $006 * * *$ & $-0.32^{* * *}$ & & & $0.36^{* * *}$ & & & & $0.06^{* * *}$ \\
\hline (2) & $-0.01^{* * *}$ & & $0.03^{* * *}$ & $0.04^{* * *}$ & $-0.05^{* * *}$ & $-0.02^{* * *}$ & $0.01^{* *}$ & 0.00 & $-0.04^{* * *}$ & $0.02^{* * *}$ & 0.00 & 0.00 & $-0.01^{* *}$ & $-0.01^{*}$ & $0.02^{* * *}$ & $0.01^{* * *}$ \\
\hline (3) & $0.03^{* * *}$ & $0.04^{* * *}$ & & $0.22^{* * *}$ & $-0.06^{* * *}$ & $-0.18^{* * *}$ & $-0.01^{* * *}$ & $-0.04^{* * *}$ & $-0.02^{* * *}$ & $0.01^{* * *}$ & $-0.04^{* * *}$ & $-0.06^{* * *}$ & $0.03^{* * *}$ & $0.06^{* * *}$ & $-0.08^{* * *}$ & $0.05^{* * *}$ \\
\hline (4) & 0.00 & $0.04^{* * *}$ & $0.35^{* * *}$ & & $-0.04^{* * *}$ & $-0.12^{* * *}$ & $0.01^{* * *}$ & $-0.03^{* * *}$ & $-0.03^{* * *}$ & $0.01^{*}$ & $-0.02^{* * *}$ & $-0.01^{* * *}$ & 0.00 & $0.01^{* * *}$ & $0.01^{* *}$ & 0.00 \\
\hline (5) & $-0.27^{* * *}$ & $-0.01^{* * *}$ & $-0.03^{* * *}$ & $-0.04^{* * *}$ & & $0.38^{* * *}$ & $0.03^{* * *}$ & $0.40^{* * *}$ & $0.56^{* * *}$ & $-0.35^{* * *}$ & $0.51^{* * *}$ & $0.53^{* * *}$ & $-0.04^{* * *}$ & $-0.53^{* * *}$ & & $0.01^{* *}$ \\
\hline (6) & $-0.07^{* * *}$ & $-0.07^{* * *}$ & $-0.16^{* * *}$ & $-0.12^{* * *}$ & & & & $0.46^{* * *}$ & & $-0.28^{* * *}$ & & $0.44^{* * *}$ & $0.15^{* * *}$ & $-0.38^{* * *}$ & $0.04^{* * *}$ & $-0.12^{* * *}$ \\
\hline (7) & $-0.02^{* * *}$ & $0.01^{* * *}$ & $-0.01^{* * *}$ & $0.01^{* * *}$ & $0.03^{* * *}$ & $0.02^{* * *}$ & & 0.00 & $0.02^{* * *}$ & 0.00 & $-0.01^{* * *}$ & $0.02^{* * *}$ & 0.00 & 0.00 & 0.00 & $0.06^{* * *}$ \\
\hline (8) & $-0.04^{* * *}$ & $-0.05^{* * *}$ & $0.03^{* * *}$ & $-0.03^{* * *}$ & $0.37^{* * *}$ & $0.45^{* * *}$ & 0.00 & & $0.43^{* * *}$ & $-0.30^{* * *}$ & $0.57^{* * *}$ & $0.46^{* * *}$ & $0.19^{* * *}$ & $-0.42^{* * *}$ & $-0.06^{* * *}$ & $0.02^{* * *}$ \\
\hline (9) & $-0.44^{* * *}$ & $0.01^{*}$ & $-0.07^{* * *}$ & $-0.01^{* * *}$ & $0.49^{* * *}$ & $0.26^{* * *}$ & $0.01^{* * *}$ & $0.26^{* * *}$ & & $-0.78^{* * *}$ & $0.41^{* * *}$ & $0.60^{* * *}$ & $0.06^{* * *}$ & $-0.58^{* * *}$ & $0.19^{* * *}$ & $-0.11^{* * *}$ \\
\hline (10) & $0.26^{* * *}$ & $-0.02^{* * *}$ & $0.05^{* * *}$ & $-0.01^{*}$ & $-0.32^{* * *}$ & $-0.27^{* * *}$ & 0.00 & $-0.28^{* * *}$ & $-0.45^{* * *}$ & & $-0.48^{* * *}$ & $-0.63^{* * *}$ & $-0.02^{* * *}$ & $0.82^{* * *}$ & $-0.22^{* * *}$ & $0.11^{* * *}$ \\
\hline (11) & $-0.03^{* * *}$ & $-0.07^{* * *}$ & $0.04^{* * *}$ & $-0.04^{* * *}$ & $0.48^{* * *}$ & $0.47^{* * *}$ & $-0.01^{* * *}$ & $0.58^{* * *}$ & $0.67^{* * *}$ & $-0.52^{* * *}$ & & $0.69^{* * *}$ & $0.29^{* * *}$ & $-0.67^{* * *}$ & $0.11^{* * *}$ & 0.00 \\
\hline (12) & $-0.29^{* * *}$ & $-0.05^{* * *}$ & 0.00 & $-0.02^{* * *}$ & $0.50^{* * *}$ & $0.41^{* * *}$ & $0.02^{* * *}$ & $0.49^{* * *}$ & $0.84^{* * *}$ & $-0.69^{* * *}$ & $0.76^{* * *}$ & & $0.17^{* * *}$ & $-0.75^{* * *}$ & $0.19^{* * *}$ & $-0.10^{* * *}$ \\
\hline (13) & $0.19^{* * *}$ & $0.01^{* *}$ & 0.00 & 0.00 & $-0.06^{* * *}$ & $0.16^{* * *}$ & $0.01^{*}$ & $0.19^{* * *}$ & $-0.23^{* * *}$ & $-0.02^{* * *}$ & $0.29^{* * *}$ & $0.10^{* * *}$ & & $-0.03^{* * *}$ & $0.03^{* * *}$ & $0.06^{* * *}$ \\
\hline (14) & $0.28^{* * *}$ & $0.05^{* * *}$ & $0.01^{* * *}$ & $0.03^{* * *}$ & $-0.51^{* * *}$ & $-0.38^{* * *}$ & 0.00 & $-0.43^{* * *}$ & $-0.93^{* * *}$ & $0.85^{* * *}$ & $-0.68^{* * *}$ & $-0.80^{* * *}$ & $-0.04^{* * *}$ & & $-0.28^{* * *}$ & $0.22^{* * *}$ \\
\hline (15) & $-0.09^{* * *}$ & 0.00 & $0.02^{* * * *}$ & 0.00 & $-0.05^{* * *}$ & $0.11^{* * *}$ & -0.01 & $-0.01^{* * *}$ & $0.22^{* * *}$ & $-0.24^{* * *}$ & $0.17^{* * *}$ & $0.21^{* * * *}$ & $0.03^{* * *}$ & $-0.29^{* * *}$ & & $-0.26^{* * *}$ \\
\hline (16) & $0.05^{* * *}$ & $0.05^{* * *}$ & $0.03^{* * *}$ & $0.01^{* * *}$ & $-0.06^{* * *}$ & $-0.21^{* * *}$ & $0.05^{* * *}$ & $-0.10^{* * *}$ & $-0.19^{* * *}$ & $0.19^{* * *}$ & $-0.20^{* * *}$ & $-0.24^{* * *}$ & 0.00 & $0.11^{* * *}$ & $-0.30^{* * *}$ & \\
\hline
\end{tabular}




\section{Table 3: Relation between off-exchange trading and intraday inefficiency (variance ratios)}

Panel A report results for panel regressions explaining how intraday variance ratios vary with offexchange trading $(\mathrm{OFFEXCH})$ in the main sample. Average daily variance ratio $\left(V R A T I O_{k l / l}=\right.$ $\left.\left|\frac{\sigma_{k l}^{2}}{k \sigma_{l}^{2}}-1\right|\right)$ over the pre-announcement window is measured over three alternative combinations of $k l$-minute and $l$-minute mid-quote return variances: (5-minutes, 1 -mintue), (15-minutes, 5minutes), and (30-minutes, 15-minutes). All independent variables are ranked into deciles by calendar quarter and assigned values between -0.5 (lowest decile) and 0.5 (highest decile). The main sample includes 74,190 firm-quarters from 2009Q1 to 2017Q2. t-statistics are based on standard errors clustered by both firms and quarters. Panels B and C report OLS regression results of the following model for the Tick Size Pilot sample: $Y_{i, t}=T_{R E A T_{i, t}}{ }^{*}{ } O S T_{i, t}+$ Firm Fixed Effects + Date Fixed Effects $+v_{i, t}$, where $Y_{i, t}$ is the percentage of off-exchange trading $(\mathrm{OFFEXCH})$ or a liquidity measure (effective spread and natural logarithm of dollar depth at NBBO) in Panel B and daily variance ratio $\left(\mathrm{VRATIO}_{\mathrm{k} / / 1}\right)$ in Panel C. TREAT is a dummy variable equal to 1 if a stock belongs to the treatment group (SEC test group 3), and 0 if a stock belongs to the control group (SEC test group 1). POST is a dummy variable equal to 1 if the trading day is from a one-year window after the stock is phased into the SEC pilot program. The Tick Size Pilot sample includes 335,653 firm-days from October 2015 to October 2017.

${ }^{*},{ }^{* *},{ }^{* * *}$ denote two-tailed $\mathrm{p}$-value $<0.10,<0.05,<0.01$, respectively. See Appendix for details of variables.

Panel A: Relation between variance ratios (VRATIO) and OFFEXCH in the main sample

\begin{tabular}{|c|c|c|c|c|c|c|}
\hline & $\begin{array}{c}(1) \\
5 \mathrm{~m} / 1 \mathrm{~m}\end{array}$ & $\begin{array}{c}(2) \\
15 \mathrm{~m} / 5 \mathrm{~m}\end{array}$ & $\begin{array}{c}(3) \\
30 \mathrm{~m} / 15 \mathrm{~m}\end{array}$ & $\begin{array}{c}(4) \\
5 \mathrm{~m} / 1 \mathrm{~m}\end{array}$ & $\begin{array}{c}(5) \\
15 \mathrm{~m} / 5 \mathrm{~m}\end{array}$ & $\begin{array}{c}(6) \\
30 \mathrm{~m} / 15 \mathrm{~m}\end{array}$ \\
\hline OFFEXCH & $\begin{array}{c}-0.005^{*} \\
-1.69\end{array}$ & $\begin{array}{c}-0.019^{* * *} \\
-6.67\end{array}$ & $\begin{array}{c}-0.026^{* * *} \\
-12.24\end{array}$ & $\begin{array}{c}-0.011^{* * *} \\
-7.49\end{array}$ & $\begin{array}{c}-0.010^{* * *} \\
-6.21\end{array}$ & $\begin{array}{c}-0.008^{* * *} \\
-5.49\end{array}$ \\
\hline IDVOL & & & & $\begin{array}{c}-0.006^{* * *} \\
-2.89\end{array}$ & $\begin{array}{c}0.006^{* * *} \\
2.71\end{array}$ & $\begin{array}{c}0.016^{* * *} \\
5.86\end{array}$ \\
\hline BETA & & & & $\begin{array}{c}-0.004^{*} \\
-1.89\end{array}$ & $\begin{array}{c}0.010^{* * *} \\
5.25\end{array}$ & $\begin{array}{c}0.018^{* * *} \\
15.30\end{array}$ \\
\hline SIZE & & & & $\begin{array}{c}-0.015^{* * *} \\
-3.53\end{array}$ & $\begin{array}{c}0.020^{* * *} \\
4.87\end{array}$ & $\begin{array}{c}0.047^{* * *} \\
13.13\end{array}$ \\
\hline BTM & & & & $\begin{array}{c}-0.002^{*} \\
-1.92\end{array}$ & $\begin{array}{c}-0.005^{* * *} \\
-4.46\end{array}$ & $\begin{array}{c}-0.004^{* * *} \\
-4.19\end{array}$ \\
\hline MOM11 & & & & $\begin{array}{c}0.001 \\
1.05\end{array}$ & $\begin{array}{c}-0.003^{* * *} \\
-2.85\end{array}$ & $\begin{array}{c}-0.002^{*} \\
-1.66\end{array}$ \\
\hline INTERCEPT & $\begin{array}{c}0.212^{* * *} \\
129.32 \\
\end{array}$ & $\begin{array}{c}0.256^{* * *} \\
192.81 \\
\end{array}$ & $\begin{array}{c}0.265^{* * *} \\
196.25 \\
\end{array}$ & $\begin{array}{c}0.212^{* * *} \\
129.47\end{array}$ & $\begin{array}{c}0.256^{* * *} \\
193.09 \\
\end{array}$ & $\begin{array}{c}0.265^{* * *} \\
198.24 \\
\end{array}$ \\
\hline Adj. $R^{2}$ & $0.19 \%$ & $2.68 \%$ & $4.92 \%$ & $1.17 \%$ & $5.47 \%$ & $16.61 \%$ \\
\hline
\end{tabular}




\section{Table 3 (continued)}

Panel B: Impact of Tick Size Pilot on the level of off-exchange trading and market liquidity

\begin{tabular}{lccc}
\hline & OFFEXCH & ESPD & DEP \\
\hline TREAT*POST & $-0.141^{* * *}$ & $-0.00070^{* * *}$ & $0.14329^{* * *}$ \\
& -172.43 & -14.95 & 36.04 \\
Firm Fixed Effects & Yes & Yes & Yes \\
Date Fixed Effects & Yes & Yes & Yes \\
\hline \# Obs. & 335,653 & 335,653 & 335,653 \\
Adj. $\mathrm{R}^{2}$ & $41 \%$ & $39.00 \%$ & $67.00 \%$ \\
\hline
\end{tabular}

Panel C: Impact of Tick Size Pilot on variance ratios (VRATIO)

\begin{tabular}{lccc}
\hline & $(1)$ & $(2)$ & $(3)$ \\
Interval & $5 \mathrm{~m} / 1 \mathrm{~m}$ & $15 \mathrm{~m} / 5 \mathrm{~m}$ & $30 \mathrm{~m} / 15 \mathrm{~m}$ \\
\hline & & & \\
TREAT*POST & $0.00283^{* *}$ & $0.00280^{* *}$ & $0.00281^{* *}$ \\
& 2.20 & 1.96 & 2.02 \\
Firm Fixed Effects & Yes & Yes & Yes \\
Date Fixed Effects & Yes & Yes & Yes \\
\hline \# Obs. & 334,435 & 334,435 & 334,434 \\
Adj. $\mathrm{R}^{2}$ & $4.00 \%$ & $3.00 \%$ & $3.00 \%$ \\
\hline
\end{tabular}




\section{Table 4: Relation between off-exchange trading (OFFEXCH) and post-earnings announcement drift (PEAD) in main sample}

Panels A and B report results for panel regressions predicting next quarter's size-adjusted returns (SARET $\left.\mathrm{q}_{+1}\right)$ based on earnings surprise measured as earnings announcement return (EARET) and analyst forecast error (FE), respectively. The interaction term between earnings surprise and off-exchange trading (OFFEXCH) estimates how PEAD (delayed price response per unit of earnings surprise) varies with OFFEXCH. All independent variables are ranked into deciles by calendar quarter and assigned values between -0.5 (lowest decile) and 0.5 (highest decile). Panel B includes all control variables considered in Panel A, but some coefficient estimates are not tabulated for brevity. The sample includes 74,190 firm-quarters from 2009Q1 to 2017Q2. t-statistics are based on standard errors clustered by both firms and quarters. See Appendix for details of variables. ${ }^{*}{ }^{* *},{ }^{* * *}$ denote two-tailed p-value $<0.10,<0.05,<0.01$, respectively.

Panel A: Relation between OFFEXCH and PEAD for earnings surprise = EARET.

\begin{tabular}{|c|c|c|c|c|c|c|c|}
\hline Variable & $(1)$ & $(2)$ & $(3)$ & $(4)$ & $(5)$ & $(6)$ & $(7)$ \\
\hline \multirow[t]{2}{*}{ EARET } & $0.026^{* * *}$ & $0.022^{* * *}$ & $0.028^{* * *}$ & $0.029^{* * *}$ & $0.028^{* * *}$ & $0.028^{* * *}$ & $0.028^{* * *}$ \\
\hline & 4.88 & 4.24 & 5.23 & 5.33 & 5.24 & 5.28 & 5.26 \\
\hline \multirow[t]{2}{*}{ EARET*OFFEXCH } & & $0.097^{* * *}$ & $0.093^{* * *}$ & $0.056^{* * *}$ & $0.055^{* * *}$ & $0.058^{* * *}$ & $0.058^{* * *}$ \\
\hline & & 8.89 & 9.13 & 4.81 & 4.68 & 4.59 & 4.60 \\
\hline \multirow[t]{2}{*}{ EARET*LOSS } & & & -0.007 & $-0.013^{*}$ & -0.013 & -0.012 & -0.012 \\
\hline & & & -0.88 & -1.67 & -1.60 & -1.45 & -1.43 \\
\hline \multirow[t]{2}{*}{ EARET*FQ4 } & & & $-0.024^{* * *}$ & $-0.024^{* * *}$ & $-0.024^{* * *}$ & $-0.024^{* * *}$ & $-0.024^{* * *}$ \\
\hline & & & -3.22 & -3.22 & -3.23 & -3.24 & -3.24 \\
\hline \multirow[t]{2}{*}{ EARET*EVOL } & & & $0.018^{* *}$ & 0.007 & 0.007 & 0.010 & 0.010 \\
\hline & & & 2.10 & 0.86 & 0.81 & 1.13 & 1.09 \\
\hline \multirow[t]{2}{*}{ EARET*ESPD } & & & & $0.079^{* * *}$ & $0.070^{* * *}$ & $0.074^{* * *}$ & $0.072^{* * *}$ \\
\hline & & & & 6.56 & 4.01 & 4.06 & 3.56 \\
\hline \multirow[t]{2}{*}{ EARET*DEP } & & & & & -0.011 & -0.012 & -0.011 \\
\hline & & & & & -1.03 & -1.05 & -0.97 \\
\hline \multirow[t]{2}{*}{ EARET*IDVOL } & & & & & & -0.012 & -0.013 \\
\hline & & & & & & -0.88 & -0.98 \\
\hline \multirow[t]{2}{*}{ EARET*VAR } & & & & & & & 0.004 \\
\hline & & & & & & & 0.17 \\
\hline \multirow[t]{2}{*}{ OFFEXCH } & & -0.001 & 0.001 & 0.000 & 0.004 & 0.007 & 0.007 \\
\hline & & -0.15 & 0.16 & 0.00 & 0.59 & 1.28 & 1.27 \\
\hline \multirow[t]{2}{*}{ LOSS } & & & -0.009 & -0.008 & -0.008 & -0.007 & -0.007 \\
\hline & & & -1.53 & -1.48 & -1.45 & -1.39 & -1.43 \\
\hline \multirow[t]{2}{*}{ FQ4 } & & & 0.004 & 0.004 & 0.004 & 0.004 & 0.004 \\
\hline & & & 0.89 & 0.91 & 0.91 & 0.90 & 0.90 \\
\hline \multirow[t]{2}{*}{ EVOL } & & & 0.002 & 0.002 & 0.003 & 0.006 & 0.006 \\
\hline & & & 0.36 & 0.39 & 0.68 & 1.43 & 1.40 \\
\hline \multirow[t]{2}{*}{ ESPD } & & & & 0.014 & 0.012 & 0.013 & 0.010 \\
\hline & & & & 1.27 & 1.15 & 1.30 & 0.95 \\
\hline
\end{tabular}




\begin{tabular}{|c|c|c|c|c|c|c|c|}
\hline DEP & & & & & $\begin{array}{c}-0.030^{* * *} \\
-363\end{array}$ & $\begin{array}{c}-0.029^{* * *} \\
-3.47\end{array}$ & $\begin{array}{c}-0.028^{* * *} \\
-3.36\end{array}$ \\
\hline \multirow[t]{2}{*}{ IDVOL } & & & & & & -0.014 & $-0.016^{*}$ \\
\hline & & & & & & -1.44 & -1.87 \\
\hline \multirow[t]{2}{*}{ VAR } & & & & & & & 0.006 \\
\hline & & & & & & & 0.61 \\
\hline \multirow[t]{2}{*}{ BETA } & 0.005 & 0.005 & 0.006 & 0.006 & 0.006 & 0.010 & 0.009 \\
\hline & 0.37 & 0.38 & 0.53 & 0.48 & 0.48 & 0.86 & 0.85 \\
\hline \multirow[t]{2}{*}{ SIZE } & -0.005 & -0.007 & -0.009 & 0.003 & $0.030^{* *}$ & 0.024 & 0.024 \\
\hline & -0.76 & -1.00 & -1.15 & 0.30 & 2.18 & 1.54 & 1.54 \\
\hline \multirow[t]{2}{*}{ BTM } & 0.004 & 0.003 & 0.002 & 0.003 & 0.003 & 0.003 & 0.003 \\
\hline & 0.43 & 0.34 & 0.27 & 0.29 & 0.36 & 0.29 & 0.29 \\
\hline \multirow[t]{2}{*}{ MOM11 } & 0.012 & 0.012 & 0.010 & 0.010 & 0.009 & 0.009 & 0.009 \\
\hline & 1.12 & 1.09 & 0.97 & 0.94 & 0.88 & 0.89 & 0.91 \\
\hline \multirow[t]{2}{*}{ INTERCEPT } & $0.005^{*}$ & $0.005^{*}$ & $0.007^{* *}$ & $0.006^{* *}$ & $0.006^{* *}$ & $0.006^{* *}$ & $0.006^{* *}$ \\
\hline & 1.74 & 1.87 & 2.37 & 2.31 & 2.29 & 2.17 & 2.19 \\
\hline Adj. $R^{2}$ & $0.16 \%$ & $0.35 \%$ & $0.39 \%$ & $0.46 \%$ & $0.51 \%$ & $0.52 \%$ & $0.52 \%$ \\
\hline
\end{tabular}

Panel B: Relation between OFFEXCH and PEAD for earnings surprise $=$ FE.

\begin{tabular}{|c|c|c|c|c|c|c|c|}
\hline Variable & $(1)$ & $(2)$ & (3) & (4) & $(5)$ & $(6)$ & $(7)$ \\
\hline \multirow[t]{2}{*}{$\mathrm{FE}$} & $0.025^{* * *}$ & $0.018^{* * *}$ & $0.028^{* * *}$ & $0.025^{* * *}$ & $0.025^{* * *}$ & $0.026^{* * *}$ & $0.026^{* * *}$ \\
\hline & 5.72 & 4.36 & 6.36 & 5.81 & 5.85 & 6.15 & 6.18 \\
\hline \multirow[t]{2}{*}{ FE*OFFEXCH } & & $0.063^{* * *}$ & $0.073^{* * *}$ & $0.033^{* * *}$ & $0.037^{* * *}$ & $0.039^{* * *}$ & $0.039^{* * *}$ \\
\hline & & 6.12 & 7.75 & 2.67 & 2.99 & 3.11 & 3.15 \\
\hline \multirow[t]{2}{*}{ FE*LOSS } & & & -0.006 & -0.011 & -0.011 & -0.011 & -0.011 \\
\hline & & & -0.69 & -1.31 & -1.31 & -1.27 & -1.34 \\
\hline \multirow[t]{2}{*}{ FE*FQ4 } & & & $-0.033^{* * *}$ & $-0.033^{* * *}$ & $-0.033^{* * *}$ & $-0.033^{* * *}$ & $-0.033^{* * *}$ \\
\hline & & & -6.96 & -6.86 & -6.81 & -6.81 & -6.83 \\
\hline \multirow[t]{2}{*}{ FE*EVOL } & & & $-0.021^{* *}$ & $-0.030^{* * *}$ & $-0.029^{* * *}$ & $-0.027^{* * *}$ & $-0.028^{* * *}$ \\
\hline & & & -2.19 & -3.13 & -3.13 & -2.73 & -2.89 \\
\hline \multirow[t]{2}{*}{ FE*ESPD } & & & & $0.077^{* * *}$ & $0.058^{* * *}$ & $0.062^{* * *}$ & $0.045^{* *}$ \\
\hline & & & & 5.51 & 3.08 & 3.35 & 2.56 \\
\hline \multirow[t]{2}{*}{$\mathrm{FE}^{*} \mathrm{DEP}$} & & & & & -0.020 & -0.020 & -0.017 \\
\hline & & & & & -1.23 & -1.22 & -1.02 \\
\hline \multirow[t]{2}{*}{ FE*IDVOL } & & & & & & -0.010 & -0.021 \\
\hline & & & & & & -0.69 & -1.45 \\
\hline \multirow[t]{2}{*}{ FE*VAR } & & & & & & & $0.033^{*}$ \\
\hline & & & & & & & 1.90 \\
\hline Controls & Yes & Yes & Yes & Yes & Yes & Yes & Yes \\
\hline Adj. $R^{2}$ & $0.16 \%$ & $0.24 \%$ & $0.30 \%$ & $0.37 \%$ & $0.42 \%$ & $0.44 \%$ & $0.44 \%$ \\
\hline
\end{tabular}




\section{Table 5: Impact of Tick Size Pilot Program on post-earnings-announcement-drift}

Panels A report OLS regression results of the following model $S A R E T_{i, q+1}=S U R_{i, q}+B E T A_{i, q}+S I Z E_{i, q}+$ $B T M_{i, q}+M O M 11_{i, q}+v_{i, q}$, where SUR is earnings surprise defined as forecast error (FE) or earnings announcement return (EARET). Panel B report OLS regression results of the following model: $S A R E T_{i, q+1}=S U R_{i, q}+$ TREAT $_{i, q} * P O S T_{i, q}+$ Firm Fixed Effects + Date Fixed Effects + $S U R_{i, q} * T_{R E A T}{ }_{i, q}{ }^{*} P_{i, q} T_{i, q}+S U R_{i, q} *$ Firm Fixed Effects $+S U R_{i, q}{ }^{*}$ Date Fixed Effects + BETA $_{i, q}+$ SIZE $_{i, q}+$ $B T M_{i, q}+M_{O M} 11_{i, q}+v_{i, t}$. In all panels, TREAT is a dummy variable equal to 1 if a stock belongs to the treatment group (SEC test group 3), and 0 if a stock belongs to the control group (SEC test group 1). $P O S T$ is a dummy variable equal to 1 if the earnings announcement date is from a one-year window after the stock is phased into the SEC pilot program. All independent variables are ranked into deciles by calendar quarter and assigned values between -0.5 (lowest decile) and 0.5 (highest decile). The sample includes 4,580 firm-quarters from 2015Q3 to 2017Q2.

${ }^{*},{ }^{* *},{ }^{* * *}$ denote two-tailed $\mathrm{p}$-value $<0.10,<0.05,<0.01$, respectively. See Appendix for details of variables.

Panel A: Post-earnings-announcement-drift in the Tick Size Pilot sample

SUR $=$ EARET $\quad$ SUR $=$ FE

\begin{tabular}{lcc} 
SUR & $0.029^{* * *}$ & -0.004 \\
& 2.79 & -0.36 \\
Controls & Yes & Yes \\
\hline \# Obs. & 4,580 & 3,930 \\
Adj. $\mathrm{R}^{2}$ & $0.28 \%$ & $0.15 \%$ \\
\hline
\end{tabular}

Panel B: Impact of Tick Size Pilot on post-earnings-announcement-drift

\section{SUR $=$ EARET}

SUR

TREAT*POST

SUR*TREAT*POST

Firm Fixed Effects

Quarter Fixed Effects

SUR*Firm Fixed Effects

SUR*Quarter Fixed Effects

Controls

\# Obs.

Adj. $\mathrm{R}^{2}$
0.300

1.47

0.011

0.76

$-0.105^{* *}$

$-2.25$

Yes

Yes

Yes

Yes

Yes

4,580

$35.00 \%$
$\mathrm{SUR}=\mathrm{FE}$

$-0.929$

$-0.92$

0.009

0.60

0.002

0.03

Yes

Yes

Yes

Yes

Yes

3,930

$38.00 \%$ 